
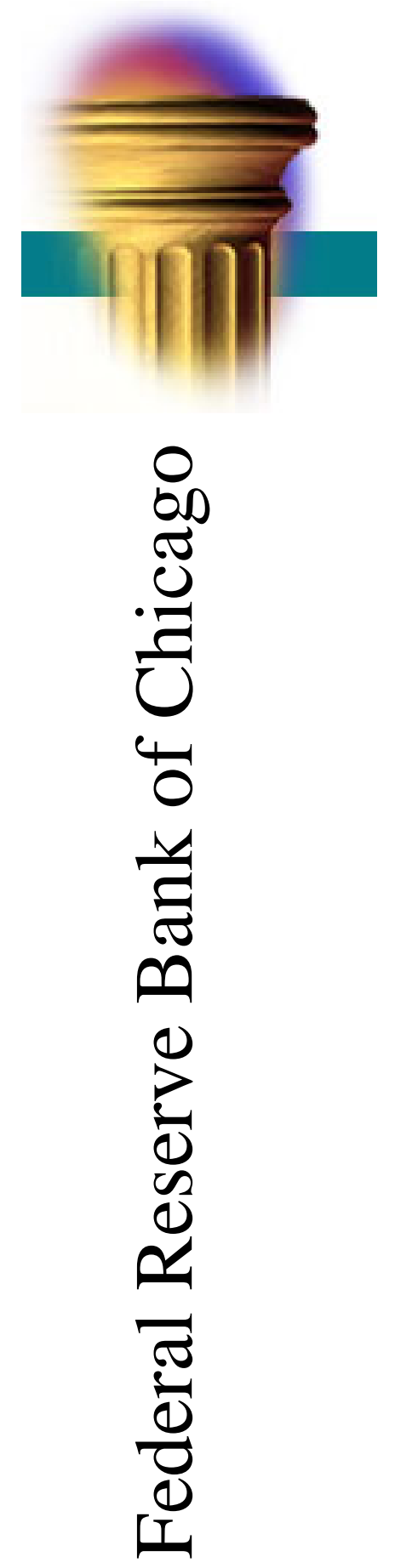

\title{
What Drives Bank Funding Spreads?
}

Thomas B. King and Kurt F. Lewis

November 2014

WP 2014-23 


\title{
What Drives Bank Funding Spreads? ${ }^{1}$
}

\author{
Thomas B. King ${ }^{\mathrm{a}}$ and Kurt F. Lewis ${ }^{\mathrm{b}}$ \\ ${ }^{a}$ Federal Reserve Bank of Chicago, 230 South LaSalle Street, Chicago, Illinois 60604 \\ ${ }^{\mathrm{b}}$ Federal Reserve Board, 20th Street and Constitution Avenue NW, Washington, DC 20551
}

\begin{abstract}
We use matched, bank-level panel data on Libor submissions and credit default swaps to decompose bank-funding spreads at several maturities into components reflecting counterparty credit risk and funding-market liquidity. To account for the possibility that banks may strategically misreport their funding rates in the Libor survey, we nest our decomposition within a model of the costs and benefits of lying. We find that Libor spreads typically consist mostly of a liquidity premium and that this premium declined at short maturities following Federal Reserve interventions in bank funding markets. At longer maturities, credit risk explains much of the time variation in Libor, reflecting in part fluctuations in the degree to which default risk is priced in the interbank market. Our results are consistent with banks both under- and over-reporting their funding costs during the crisis but suggest that the incidence of this behavior may have subsequently declined.
\end{abstract}

Key words: LIBOR, Liquidity, Credit Risk, Misreporting

Email addresses: thomas.king@chi.frb.org (Thomas B. King), kurt.f.lewis@frb.gov (Kurt F. Lewis).

1 We thank seminar participants at the Federal Reserve Banks of Chicago and Kansas City, the Federal Reserve Board, and the Bank of England for helpful comments. The analysis and conclusions contained here are those of the authors and do not indicate concurrence by other members of the research staff or reflect official positions of any part of the Federal Reserve System. 


\section{Introduction}

During the financial crisis that began in 2007, bank funding markets came under extraordinary pressure, threatening both the functioning of the financial system and the transmission of monetary policy. Perhaps the most frequently cited measures of the strains in these markets were the spreads between the London Interbank Offer Rate (Libor) and comparable-maturity rates that could be considered "risk free," such as the rate on overnight index swaps (OIS). Indeed, at the height of the turmoil, the one-month Libor-OIS spread, which was typically less than 10 basis points prior to mid-2007, rose to nearly 300 basis points. Because of the critical role of Libor and similar rates in the functioning of financial markets and stability of financial institutions, several papers have studied their behavior of during and after the crisis. ${ }^{2}$ A central issue in these studies is the degree to which bank funding conditions are driven by counterparty credit risk versus market liquidity. This question has relevance for, among other things, the ability of central banks to relieve strains in funding markets and the design of policies for doing so. It is also important for informing and testing theoretical models of the interbank market in which credit risk and liquidity play a role, such as Eisenschmidt and Tapking (2009), Heider et al. (2009), and Acharya and Skeie (2011).

In this paper, we use panel data on individual banks' dollar Libor submissions and the spreads on their credit default swaps (CDS) to address this problem. The cross-sectional dimension of our data brings to bear a considerable amount of information that has been largely unexploited by previous studies and, in particular, gives us a robust way of identifying the liquidity and credit-risk components in the term structure of Libor. We also confront another issue that has been ignored by the literature focused on this question: Libor is based on a survey of banks that essentially report on an honor system, and it is now well known that at least some of those banks frequently lied about their borrowing rates either for reputational reasons or in an attempt to influence the direction of market rates for financial gain (see, for example, Hou and Skeie (2014)). A few papers have recently begun to examine the consequences of misreporting for the distribution of Libor quotes by modeling aspects of the game played by banks, but none has yet considered the implications for the creditliquidity decomposition.

In our analysis, we estimate and correct for the effects of lying about Libor by assuming that the costs and benefits of misreporting have a simple linear-quadratic structure. The model of reporting incentives is similar to Youle (2014), who also adopts a quadratic cost of deviating from the truth, but we build on his framework in two significant ways. First, we allow the incentives for misreporting to vary over time (in Youle's estimation they are constant for each bank); we treat these incentives as unobserved state variables and estimate them with the Kalman filter. Second, we include the possibility that banks face a cost of submitting a Libor quote that is much different from the average of other banks' quotes on the same day. This piece of the model, which captures a bank's reluctance to appear as an outlier, provides one mechanism through which Libor quotes can be highly correlated with aggregate credit

2 See McAndrews et al. (2008); Taylor and Williams (2009); Schwarz (2014); Gefang et al. (2011); Wu (2011); Smith (2012); Filipović and Trolle (2013); and Christensen et al. (2014). 
risk even though they are not highly correlated with individual credit risk - a striking and otherwise puzzling feature of the panel data.

Controlling for misreporting in this way, we find that the average levels of Libor-OIS spreads during and after the financial crisis mostly consist of the liquidity component, and this component tends to be relatively larger at longer maturities than at short maturities. We estimate that liquidity improved significantly at shorter maturities in October 2008 and, to a lesser extent, in December 2007, following Federal Reserve interventions in short-term funding markets that targeted those maturities. However - outside of those episodes - we find that most of the time-series variation in Libor spreads is driven by the credit-risk component. This variation reflects changes both in credit risk itself (as captured by CDS spreads) and in Libor's sensitivity to that credit risk. Sensitivity to credit risk was particularly high in 2008 and 2009 and has often been close to zero since that time.

The effect of misreporting varies across time, maturities, and banks, but we estimate that it was most pronounced during the height of the crisis. Depending on their motives, banks may have either under- or over-reported their funding costs at any point in time, so that the overall effect on the aggregate Libor rate is ambiguous. In terms of the parameters of our structural model, we estimate that banks consistently perceived the cost of reporting a value different from the average of other banks as being significantly greater than the cost of reporting a value different from the truth, explaining why the time-series correlation between Libor quotes and CDS spreads is much higher than the cross-sectional correlation. It appears that the incidence of misreporting has declined over time, consistent with a regulatory crackdown on this activity. Nonetheless, through the end of the sample it continues to be the case that individual Libor submissions bear little relation to individual CDS spreads, implying that considerable noise remains in the reporting process. ${ }^{3}$

Relative to the studies of aggregate bank-funding spreads mentioned above, our paper contributes in three key ways. First, we correct for misreporting. Since we find that the effects of misreporting are at times large, this correction is important. Second, we allow the sensitivity of Libor to credit risk to vary over time, whereas previous studies of this relationship-for example, the many papers that simply regress aggregate Libor spreads on aggregate CDS indices - have treated it as constant. Our finding that sensitivity varies significantly suggests that those models are misspecified. Finally, our use of panel data addresses an identification problem that cannot be solved with time-series data except by appeal to untestable assumptions. In particular, Taylor and Williams (2009) argue that the widening of LiborOIS spreads during the crisis mostly reflected a decline in the perceived creditworthiness of borrowing banks and that Federal Reserve lending facilities, which primarily served to inject liquidity into the market, could therefore not have had much impact. But, as pointed out by Schwarz (2014) and others, Taylor and Williams's finding relies on their treatment of liquidity as a regression residual, which effectively attributes the maximum possible importance to credit risk. Other papers address this issue by imposing term structure restrictions (Smith (2012); Filipović and Trolle (2013); Christensen et al. (2014)), by proxying liquidity in var-

3 For a recent discussion of policy considerations surrounding Libor reform, see Duffie and Stein (2014). 
ious ways Schwarz (2014), or by using other time-series techniques (for example, Gefang et al. (2011)). ${ }^{4}$

Our paper also relates to the literature that tests for interbank market discipline in panel and cross-sectional bank-level data [e.g., Furfine (2001); Ashcraft and Bleakley (2006); King (2008)]. Like those studies, but using a novel dataset and approach, we demonstrate that credit risk is priced in the bank funding market, although the degree varies over time. It is particularly interesting to compare our results to Afonso et al. (2011), who regress borrowing rates inferred from Fedwire transactions against credit-risk measures based on call report data. As they do, we estimate that the sensitivity of individual banks' borrowing costs to their credit risk increased in the immediate wake of the Lehman failure. However, we also estimate that this sensitivity subsequently retreated and was close to zero by the end of our sample. Moreover, we find that the importance of the liquidity premium for funding costs was at least as large, even during the height of the crisis.

The paper proceeds as follows. We begin in the following section by reviewing the construction and matching of the Libor and CDS data, and we motivate the model of misreporting that follows by pointing out certain features of these data that are hard to reconcile. In Section 3, we develop a simple theoretical model to motivate and help interpret our empirical tests. Section 4 describes the econometric procedure used to identify the credit-risk, liquidity, and misreporting components, and Section 5 presents the results. Section 6 concludes the paper.

\section{Background and Data}

\subsection{Construction of the Data}

Libor is calculated based on a daily survey of a panel of large banks in North America, Europe, and Japan. Prior to 2014, this survey was conducted by the British Bankers Association; it is now administered by Intercontinental Exchange. The survey question is: "At what rate could you borrow funds, were you to do so by asking for and then accepting inter-bank offers in a reasonable market size just prior to 11 am?" Every day, this question is answered by a respondent at each of the panel banks for ten maturities (up to one year) and five currencies. The composition of the survey panel varies across currencies and also changes over time. The aggregate value that is published as "the" Libor reference rate for each currency at each maturity on each day is calculated as the trimmed mean of the survey responses,

4 Gefang et al. (2011) also use panel data on CDS and Libor quotes, but they do not match these data at the bank level as we do. Rather, they model credit risk as due to a single unobserved factor, which drives both Libor and CDS with different loadings at each bank. Thus, their identification comes mostly from the time-series component of the data. 


\begin{tabular}{l|cc}
\multicolumn{1}{c|}{ Bank } & First date in sample & Last date in sample \\
\hline Bank of America & $8 / 1 / 2007$ & $6 / 28 / 2013$ \\
Bank of Tokyo-Mitsubishi & $8 / 1 / 2007$ & $6 / 28 / 2013$ \\
Barclays & $8 / 1 / 2007$ & $6 / 28 / 2013$ \\
BNP Paribas & $2 / 1 / 2011$ & $6 / 28 / 2013$ \\
Citibank & $8 / 1 / 2007$ & $6 / 28 / 2013$ \\
Credit Agricole & $2 / 1 / 2011$ & $6 / 28 / 2013$ \\
Credit Suisse & $5 / 23 / 2008$ & $6 / 28 / 2013$ \\
Deutsche Bank & $8 / 1 / 2007$ & $6 / 28 / 2013$ \\
HSBC & $8 / 2 / 2007$ & $6 / 28 / 2013$ \\
JP Morgan Chase & $8 / 1 / 2007$ & $6 / 28 / 2013$ \\
Norinchukin Bank & $8 / 2 / 2007$ & $6 / 28 / 2013$ \\
Rabobank & $8 / 1 / 2007$ & $6 / 28 / 2013$ \\
Royal Bank of Canada & $8 / 1 / 2007$ & $8 / 25 / 2009$ \\
Royal Bank of Scotland & $8 / 14 / 2007$ & $6 / 28 / 2013$ \\
Societe Generale & $2 / 9 / 2009$ & $6 / 28 / 2013$ \\
Somitomo Mitsui & $2 / 1 / 2011$ & $6 / 28 / 2013$ \\
UBS & $8 / 1 / 2007$ & $6 / 28 / 2013$
\end{tabular}

Table 1

Composition of sample data

where the trimming excludes the $25 \%$ highest and $25 \%$ lowest submissions rounded to the nearest integer number of respondents. ${ }^{5}$

The primary data used in this paper consist of the daily bank-level dollar Libor quotes and matched CDS spreads on a subset of the dollar-Libor-panel banks for maturities up to one year. We obtain CDS quotes for the senior debt of the banks from Markit and the Libor data from Bloomberg. We have Libor quotes for every bank that was in the panel at each point in time, but we only use a subset of these quotes because a few banks did not always have CDS traded in sufficient depth for Markit to report their spreads. The firms for which we have the most data have Libor quotes dating back to the late 1990s, and CDS data beginning in 2001. However, as shown below, there is virtually no interesting variation in either variable prior to the crisis; we therefore focus our analysis on the period beginning in August 2007. By the middle of that month, our CDS data include twelve of the sixteen banks that were on the dollar Libor panel at the time. By the end of our sample, in June 2013, the panel had grown to eighteen banks, and we have CDS data for seventeen of them. We exclude one bank, Lloyds, because even though some CDS data exist for this institution they are too sparse to allow us to run our model reliably. (For example, we only have a six-month CDS quote for Lloyds on a single day of our sample period.) Table 1 provides information on the composition of our dataset over time. ${ }^{6}$

5 According to the BBA, the panels of banks are selected to reflect three principles: (1) "scale of market activity," (2) credit rating, and (3) "perceived expertise in the currency concerned." Prior to the first round of reforms requested by the UK's Financial Conduct Authority, Libor was reported for ten currencies and fifteen maturities.

6 We end our sample in June 2013 because reforms in the reporting procedures for Libor were 


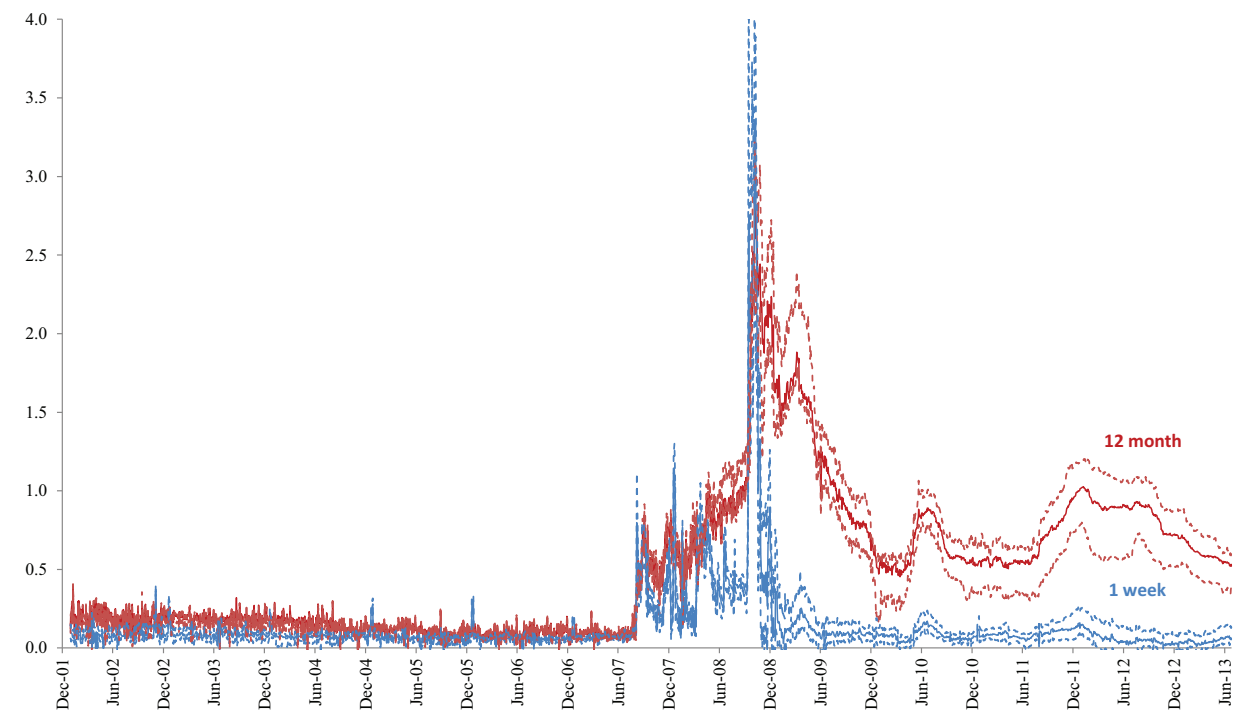

Fig. 1. Dispersion of Libos-OIS Submissions

During normal times, term Libor rates primarily reflect the market expectation of the path of short-term interest rates, perhaps with some term premium adjustment. To eliminate this component, we follow standard practice and subtract OIS rates, matched by maturity, from each bank's Libor quote on each day. ${ }^{7}$ OIS rates are obtained from Bloomberg. We refer to the difference between Libor quotes and OIS rates as "LOIS" spreads.

For accurate comparison, we need to match the maturity of the CDS and Libor submissions. While we have both CDS and Libor quotes at the six-month and twelve-month horizons, CDS are not generally quoted for maturities shorter than this. Moreover, the six- and twelve-month CDS contracts may be less liquid than their more-popular five-year counterparts, and it may therefore be advantageous to make use of the information in longer-maturity quotes as well. We therefore fit a CDS curve for each bank on each day using the form described in Nelson and Siegel (1987) and data on CDS contracts with maturities of 6 months and 1, 2, 3, 4, 5, $7,10,15,20$, and 30 years. To be sure that we fit the short end of this curve most accurately, we perform the estimation weighting each CDS quote by the inverse of its maturity, and we exclude any observation for which the 6- or 12-month CDS quote is missing. We then use fitted values from these curves to extract CDS spreads at the one-week, one-month, three-month, six-month, and twelve-month maturities for each bank on each day.

implemented at that time, likely changing the determination of those rates.

7 For most of our sample period, with overnight rates close to zero and generally expected to remain there for a year or more, OIS rates were negligible relative to the level of Libor. 


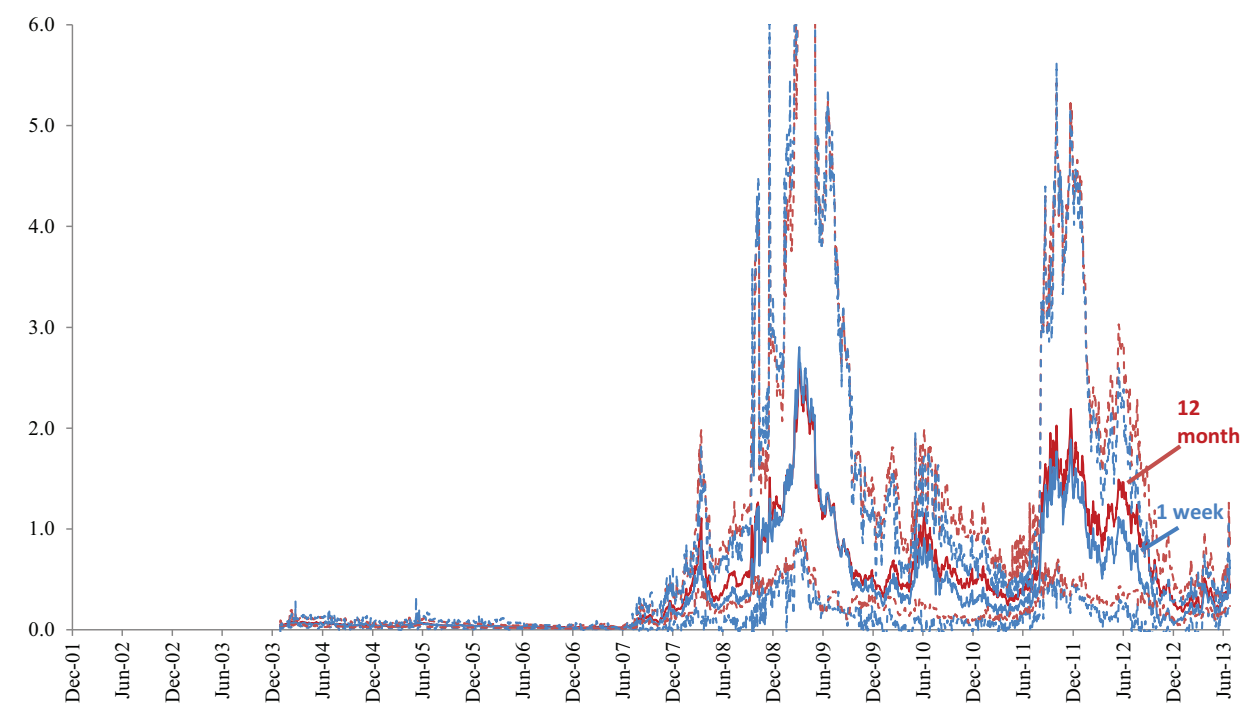

Fig. 2. Dispersion of Nelson-Seigelized CDS Quotes

\subsection{Empirical Features of Libor and CDS Spreads}

To illustrate some key features of these data, Figures 1 and 2 plot the 1-week and 12-month LOIS spreads and (Nelson-Seigelized) CDS quotes, respectively. In each case, the solid lines show the cross-sectional average on each day, and the dashed lines show the range across banks.

The LOIS and CDS data have some clear commonalities. They both are very close to zero with little cross-sectional variation prior to August 2007. After that time, the average levels of both series rise significantly, and the dispersion widens. We see increases in both series after the default of Lehman Brothers in September 2008, as well as smaller increases around the times of tensions in Europe in mid-2010 and late 2011. These comovements might suggest that at least part of the reason for the movement in LOIS has to do with the same credit-risk factors that are driving CDS spreads.

However, there are also some important differences between the two series. Most significantly, the term spread for LOIS widens substantially in the post-2007 period-the difference between the 1-month and 12-month series rises to over 150 basis points in 2009-whereas the term spread in CDS remains close to zero, at least on average. ${ }^{8}$ Thus, at least at this superficial level, it does not seem that credit risk can fully account for the widening of both short- and long-term LOIS spreads. In addition, there are distinct differences in the timing and relative magnitudes of movements in the two series. For example, the jump in LOIS

8 The flatness of the CDS curve between the 1- and 12-month rates shown in the figure is based extrapolation from our Nelson-Seigel curves. However, because the NS curves are fit with a higher weight on short maturities, they derive most of their slope information from the 6-, 12-, and 24month-maturity data. Thus, the flatness of the CDS curve in the figure reflects the fact that actual CDS quotes across these short maturities are typically very close to one another. 


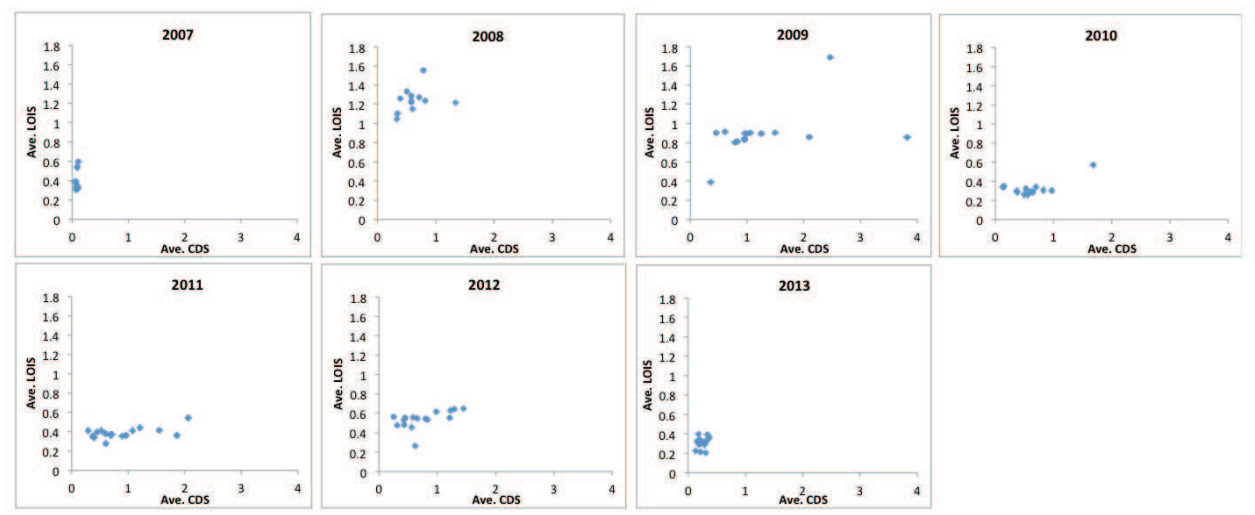

Fig. 3. Cross-sectional Relationship between Libor-OIS and CDS

spreads in August 2007 is quite abrupt, while that in CDS spreads is more gradual; after the collapse of Lehman, both spreads widen, but the LOIS spread peaks relatively quickly, in October 2008, while the average CDS spread does not peak until mid-2009; and during the European crisis in 2011, CDS spreads widen to about the same levels that they had reached in the aftermath of Lehman, but LOIS spreads widen by a much smaller amount than they had in 2008. Finally, while the cross-sectional variation of the LOIS spreads does increase somewhat after August 2007, the increase in the dispersion of the CDS spreads is far more dramatic. For example, the coefficient of variation for the 12-month CDS spread averages 0.5 after that date, while that for the corresponding LOIS spread averages just 0.1. ${ }^{9}$

Figure 3 illustrates the cross-sectional relationship between LOIS and CDS by scatterplotting the yearly average of the two series, year by year, for the six-month maturity. It is clear from these figures that the cross-sectional correlation between LOIS and CDS spreads is weak at best. ${ }^{10}$ Table 2 examines this correlation more systematically by reporting, for each maturity, averages of the daily cross-sectional correlation between LOIS and CDS spreads. Since the relationship could in principle be nonlinear, both Pearson and Spearman correlations are reported. Cross-sectional correlations are slightly stronger at longer maturities than at shorter maturities, but across the term structure they are generally very close to zero.

The weak correlation between LOIS and CDS spreads in the cross section is puzzling because, broadly speaking, interbank lenders to a given bank and the writers of CDS contracts on that bank face losses in the sames states of the world. In the United States, for example, the National Depositor Preference Act of 1993 treats both bonds and interbank loans as "general or senior liabilities," which stand together in the same place in line in the event of insolvency (after depositors but before subordinated debtholders) and, at least in principle, receive the same pro rata recovery rate. ${ }^{11}$ Even where expected recovery rates differ (as we

9 Kuo et al. (2012) show that Libor quotes also tend to be less dispersed than other measures of funding costs for the same set of banks.

${ }^{10}$ Michaud and Upper (2008) also note the weak cross-sectional correlation between CDS and Libor quotes.

${ }^{11}$ See Federal Deposit Insurance Act Section 11(d) (https://www.fdic.gov/regulations/laws/rules/1000- 


\begin{tabular}{l|cc} 
Maturity & Pearson & Spearman \\
\hline 1 week & 0.009 & 0.010 \\
1 month & -0.010 & 0.003 \\
3 month & -0.012 & 0.009 \\
6 month & 0.080 & 0.091 \\
12 month & 0.138 & 0.141
\end{tabular}

Table 2

Average daily cross-sectional correlations between Libor quotes and CDS spreads. All sample banks, $8 / 1 / 2007-6 / 28 / 2013$.

allow for in the model of Section 3), default on one claim should still imply default on the other, so we would still generally expect the correlation between the two spreads to be very high. Furthermore, it seems particularly odd that the spreads should not be correlated in the cross section given the strong correlation that the aggregate series display over time. On its face, that observation would seem to suggest that lending banks demand a premium to compensate them for the overall risk of the banking sector but not for the risk of the particular banks they are lending to.

It is tempting to appeal to information assymetries to explain these discrepancies, as in the model of Heider et al. (2009). But this cannot be the whole story because interbank lenders generally have access to contemporaneous CDS quotes when negotiating lending terms, and, during our sample period, CDS dealers also had access to contemporaneous bank-level Libor submissions. ${ }^{12}$ Indeed, many of the lending banks in the interbank market are the very banks that are also making markets in CDS, and the same information sets should thus be priced into both instruments. An alternative possibility, considered below, is that at least part of the discrepancy between LOIS and CDS spreads might be due to banks not reporting their true funding costs in the Libor survey.

\subsection{Libor Misreporting}

In the spring of 2008, the Wall Street Journal published a series of articles calling into question the veracity of Libor quotes. ${ }^{13}$ The Journal articles pointed to the weakening relationship between Libor and CDS quotes specifically as prima facie evidence of misreporting:

Until recently, the cost of insuring against banks defaulting on their debts moved largely in tandem with Libor - both rose when the market thought banks were in trouble. But beginning in late January [2008], as fears grew about possible bank failures, the two mea-

1220.html\#fdic10Note00sec.11d).

12 Beginning in July 2013, the bank-level Libor data were released only with a three-month lag.

13 Mollenkamp, C., "Bankers Cast Doubt on Key Rate Amid Crisis." Wall Street Journal, 16 April 2008; Mollenkamp, C. and Whitehouse, M., "Study Casts Doubt on Key Rate," Wall Street Journal, 29 May 2008. According to the articles, speculation about significant misreporting had already been circulating privately among market participants for several months. 
sures began to diverge, with reported Libor rates failing to reflect rising default-insurance costs, the Journal analysis shows.

The authors went on to point out several specific banks for which Libor quotes seemed particularly out of line with CDS spreads and speculated that "one possible explanation for the gap is that banks understated their borrowing rates." They also noted with suspicion the relatively low cross-sectional variance that we observed above:

At times of market turmoil, banks face a dilemma. If any bank submits a much higher rate than its peers, it risks looking like it's in financial trouble. So banks have an incentive to play it safe by reporting something similar - which would cause the reported rates to cluster together.

Subsequent to the Wall Street Journal story, most of the banks on the Libor panel have been investigated and several have settled allegations of malfeasance with U.S. and U.K authorities, collectively paying billions of dollars in fines. In addition, several individual bankers face criminal charges, with at least two having already pled guilty, and numerous civil suits have been filed. Some of these suits reflect alleged losses to government entities, including some U.S. state and local governments that had large interest-rate swaps positions linked to Libor, and the FDIC, which claims that several depository institutions that failed during the financial crisis suffered Libor-related losses that are now being passed on to taxpayers through the deposit-insurance fund. Meawhile, U.K. regulators have undertaken a set of reforms of the reporting process intended to discourage future misreporting (Wheatly, 2012). ${ }^{14}$

In addition to reputational concerns, banks may have direct financial incentives to misreport. Many of the banks on the Libor panel make markets or hold positions in Libor-linked financial products, such as interest rate derivatives and syndicated loans. If large enough, such positions could net the banks, their clients, or their traders substantial sums of money in short periods of time, even from a few-basis-point move in Libor. The incidence of positiondriven misreporting is attested to by the numerous exchanges between Libor respondents and traders that have come to light through the recent legal investigations, in which Libor submitters repeatedly submit to requests from traders at their banks for particular configurations of Libor quotes. ${ }^{15}$

$\overline{14}$ The information in this paragraph was current as of October 2014 and verified at http://graphics.wsj.com/libor-network/\#item=Hayes. In addition to the banks noted in the table, the inter-dealer brokers ICAP and R.P. Martin have paid penalties to U.S. and European authorities for helping to facilitate and coordinate rate setting across banks. We note that some of the penalties and prosecutions that have taken place have to do with Libor misreporting in currencies other than U.S. dollars, which we do not analyze.

${ }^{15}$ See, for example, Vaughan, L. and Finch, G., "Secret Libor Transcripts Expose Trader RateManipulation." Bloomberg, 13 Dec. 2012. Gandhi et al. (2012) estimate that the panel banks collectively gained $\$ 23$ billion from position-driven manipulation over the 2005-2009 period. 
Misreporting can potentially explain the low dispersion of Libor quotes and the weak crosssectional correlation between LOIS and CDS spreads. It may also explain how these spreads can still be strongly correlated in the time series. If reporting banks perceive a cost to showing up as outliers - perhaps because of reputational risk or potential regulatory scrutiny - they may have an incentive, all else equal, to write down numbers that are close to the numbers they believe other banks are going to write down on any given day. Thus, average CDS spreads can act as an attractor for LOIS spreads, even if individual bank CDS are only weakly correlated with individual LOIS.

In the wake of the scandal, a small literature has emerged on Libor misreporing. On the empirical side, Kuo et al. (2012) find that banks' bids for funding at the Federal Reserve's Term Auction Facility (which should have strictly dominated borrowing in the interbank market) were higher on average than their Libor submissions, suggesting underreporting during this period. Abrantes-Metz et al. (2012) computed summary statistics for bank-level (non-maturity matched) Libor rates and CDS spreads, for certain periods in 2008 and found it difficult to detect evidence of manipulation, but Gandhi et al. (2013) found that bank exposures to Libor-linked products were significantly correlated with their Libor quotes. Eisl et al. (2014) examine the properties of the bank-level Libor submissions in an attempt to evaluate how alternative reporting and aggregation schemes might affect outcomes.

Meanwhile, theoretical work has largely focused on the game played by banks in setting rates and the consequences for the shape of the resulting rate distribution [Snider and Youle (2012); Chen (2013); Youle (2014)]. These models have had less to say about the quantitative effects on the aggregate Libor rate and virtually nothing to say about how those effects could vary over time. In addition, the theoretical literature to date has focused almost exclusively on the cost of lying, rather than the cost of deviating from the group. The discussion above suggests that the latter may be important. We next develop a simple model that incorporates this incentive and that also connects misreporting to the liquidity and credit risk components discussed earlier.

\section{A Model of Credit Risk, Liquidity, and Misreporting}

In this section, we develop a model of Libor determination to help motivate and interpret our empirical tests. Although it is quite stripped down, the funding-cost portion of the model shares the intuition of many other models of the interbank market, with banks choosing their reserve holdings to cover expected liquidity needs [e.g., Allen et al. (2009); Eisenschmidt and Tapking (2009)]. The misreporting portion borrows features from Youle (2014) but, as noted above, also introduces an incentive for banks not to deviate too far from other banks when they report.

Consider a representative risk-neutral bank with unit measure of assets to invest and two investment opportunities: holding cash reserves or lending to $I$ potential borrowing banks. We assume that the level of reserves is fixed by the central bank and that reserve holdings 
are remunerated at the gross risk-free rate $R$. To conserve notation, we develop the model for a contract of a single maturity (one "period"). We also supress time subscripts for the moment, although in our estimation the structural parameters of the model will be allowed to change in every period and to differ across maturities.

The lending bank faces two sources of risk. First, any funds it lends in the interbank market may be defaulted on. Specifically, a loan to bank $i$ defaults with probability $\rho_{i}$. In the event of default, the lending bank loses a fraction $\delta^{L}$ of the loan and interest. For simplicity, we assume that these conditional loss rates are identical across borrowing banks, though this is not essential. Thus, the expected return on a loan is

$$
r_{i}=\frac{\left(\rho_{i}+\left(1-\rho_{i}\right) \delta^{L}\right)}{p_{i}^{L}}
$$

where $p_{i}^{L}$ is the price of an interbank loan to bank $i$ that promises to pay $\$ 1$ in the non-default state. Collect the returns in the vector $\mathbf{r}$ and the default probabilities in the vector $\rho$.

The second source of risk faced by the lending bank is a random cash outflow during the period over which its interbank loans are outstanding. Let this outflow be distributed over the support $[0,1]$ with density $f$. If the cash outflow exceeds the level of reserves that the bank has chosen to hold, the bank pays a cost $k$. This cost could reflect the cost of asset firesales, borrowing from the central bank, or, in the extreme, bankruptcy. The implications of our model are essentially unchanged if we allow for multiple lending banks, each with a different distribution $f$.

The lending bank's objective function is

$$
\max _{x, \mathbf{w}}\left\{x R+(1-x) \mathbf{w}^{\prime} \mathbf{r}-k \int_{x}^{1} f(\xi) d \xi\right\}
$$

subject to

$$
\begin{aligned}
& 0 \leq x \leq 1 \\
& 0 \leq w_{i} \leq 1 \forall i
\end{aligned}
$$

where the vector $\mathbf{w}=\left(w_{1} \ldots w_{I}\right)$ contains the portfolio weights allocated to each potential borrowing bank. The first-order condition immediately implies that the equilibrium price of a loan to any bank $i$ satisfies

$$
p_{i}^{L}=\frac{1-\delta^{L} \rho_{i}}{R\left(1+k f\left(x^{*}\right)\right)}
$$


where $x^{*}$ is the lending bank's optimal cash holding.

Meanwhile, following similar logic, a CDS contract that insures $\$ 1$ of bonds against default for one period is priced as

$$
p_{i}^{C}=1-\delta^{B} \rho_{i}
$$

where $\delta^{B}$ is the conditional loss rate on bank bonds. Note that we assume that bonds and interbank loans default in the same states of the world but may have different loss rates given default.

Since interest rates are given by negative log loan prices, for empirically relevant values of the parameters the spread of interbank loans over the risk-free rate can be written as

$$
L_{i} \approx \lambda+\phi C_{i}
$$

where $\lambda \equiv k f\left(x^{*}\right), \phi \equiv \frac{\delta^{L}}{\delta^{B}}$, and $C_{i}=-\log p_{i}^{C}$ is the CDS spread for bank $i$. If one measures the risk-free rate as the OIS rate, (5) is essentially the specification estimated by Taylor and Williams (2009) and others, who have interpreted $\lambda$ as reflecting funding-market "liquidity" and $\phi C_{i}$ as reflecting counterparty credit risk. Our model gives the parameters of this reduced form a bit more structural footing. Specifically, in this stylized model, $\lambda$ is the expected marginal cost of a cash shortfall among lending banks, and $\phi$ is the relative conditional loss rates for bondholders and interbank lenders.

To allow for potential misreporting in this framework, we distinguish between each bank $i$ 's "true" funding cost $L_{i}$ and the cost that it reports for Libor purposes $\widehat{L}_{i}$. The bank's reported value for Libor purposes may reflect several considerations, including that the bank may have a portfolio-specific reason to distort Libor in one direction or the other. Except at the trimming quantiles, the marginal effect of any bank's quote on aggregate Libor is constant (either zero or $2 / I$ ), so we assume that the benefits from distortion are approximately linear. We also consider that banks may receive reputational or signaling benefits from reporting a low value for Libor. Again, we assume that these benefits are linear in $\widehat{L}_{i}$ at each point in time. Thus, in any period, both incentives to misreport are captured by an expression of the form

$$
\text { misreporting benefits }{ }_{i}=\gamma_{1, i} \widehat{L}_{i}
$$

In theory, the marginal benefit of misreporting $\gamma_{1, i}$ can take either sign.

We assume that each bank may face a quadratic cost of reporting a value far away from the truth. This cost, which is similar to the form adopted by Youle (2014), may reflect potential regulatory or legal penalties, or simply the psychological and moral costs of lying. We define "far away from the truth" in terms of the cross-sectional dispersion of Libor quotes at each 
point in time. This reflects, in part, the idea that the probability of a lie being detected is likely lower when there is more heterogeneity in the market. Thus, we have:

$$
\text { cost of } \operatorname{lying}_{i}=\frac{\gamma_{2}}{2} \frac{\left(\widehat{L}_{i}-L_{i}\right)^{2}}{\operatorname{std}\left[\widehat{L}_{i}\right]}
$$

For simplicity, we assume that the parameter $\gamma_{2} \geq 0$ is the same across banks, although this assumption could be relaxed.

As discussed above, we also allow for the possibility that banks may worry that reporting a value much different from other banks (in either direction) may bring unwanted scrutiny by markets or regulators. We capture this incentive with a second cost function:

$$
\text { cost of being an outlier }{ }_{i}=\frac{\gamma_{3}}{2} \frac{\left(\widehat{L}_{i}-\widehat{\widehat{L}}\right)^{2}}{\operatorname{std}\left[\widehat{L}_{i}\right]}
$$

where $\gamma_{3} \geq 0$ and $\overline{\hat{L}}$ is the cross-sectional mean of Libor quotes. We assume that the moments $\widehat{\widehat{L}}$ and $\operatorname{std}[\widehat{L}]$ are known to all banks when they do their optimization. Since traders usually have a good sense of the conditions in the day's market before submitting their quotes, this seems a reasonable approximation. ${ }^{16}$

Each borrowing bank chooses $\widehat{L}_{i}$, to maximize benefits less costs in each period. One can show (see appendix A) that this optimization results in an equilibrium average Libor rate that is given by

$$
\overline{\widehat{L}}=\lambda+\phi \bar{C}+\frac{\bar{\gamma}_{1}}{\gamma_{2}} \operatorname{std}\left[\widehat{L}_{i}\right]
$$

where $\bar{C}$ is the cross-sectional mean of the CDS spreads and $\bar{\gamma}_{1}$ is the cross-sectional mean of $\gamma_{1, i}$. (From here on, we ignore the approximation error due to Jensen's inequality in equation (5).) The first two terms on the right-hand side of this equation are the liquidity and creditrisk components of the average Libor. If banks always reported the truth, the average Libor rate on any given day would be the sum of those two components. The last term is thus the bias that is introduced by misreporting. The magnitude of this bias is larger, all else equal,

\footnotetext{
${ }^{16}$ For example, in its May 29, 2008 article, the Wall Street Journal noted, "When posting rates to the BBA [British Banker's Association], the 16 panel banks don't operate in a vacuum. In the hours before banks report their rates, their traders can phone brokers at firms such as Tullett Prebon PLC, ICAP PLC and Compagnie Financière Tradition to get estimates of where brokers perceive the loan market to be."
} 
when the average benefits of misreporting are larger, when the costs of lying are smaller, and when there is more cross-sectional dispersion in Libor quotes. ${ }^{17}$

The dispersion of quotes $\operatorname{std}\left[\widehat{L}_{i}\right]$ that appears in equation (9) is endogenous. Substituting it out reveals that bank-level Libor quotes can be written in reduced form as a linear function of the liquidity premium, bank-level CDS spreads, and the cross-sectional mean and standard deviation of all banks' CDS. In particular:

$$
\widehat{L}_{i}=\lambda+\phi C_{i}+\beta_{1 i} \sigma+\beta_{2}\left(C_{i}-\bar{C}\right)
$$

where the $\beta$ terms are nonlinear combinations of the structural parameters $\phi, \gamma_{1, i}$ (for all $i), \gamma_{2}$, and $\gamma_{3}$, and $\sigma$ is the cross-sectional standard deviation of CDS quotes. ${ }^{18}$ It is this equation that will be the target of our estimation.

Since our estimation will allow us to infer $\lambda$ and $\phi$ on each day and at each maturity, equation (10) allows us estimate each bank's "true" Libor values and thus to infer the bias in Libor quotes. Although we cannot back out each of the individual $\gamma$ 's, we can use the estimates to say some things about their relative values - for example, $\beta_{1, i}$ happens to be linear in $\gamma_{1, i}$ on each day. Of course, if we can back out "true" Libor rates as econometricians, we should recognize the possibility that market participants can also do it. Our model is essentially unchanged if we permit all banks to have full knowledge of all of the $L_{i}$ in real time. Of course, in this case, it would not make sense to consider reputational benefits of misreporting, but equation (6) still holds as an approximation to possible trading gains.

\section{Estimation}

We estimate the model by treating equation (10) as a measurement equation for each bank at each maturity and allowing the parameters of these equations to vary over time. We introduce the subscript $m$ to indicate a contract's maturity and the subscript $t$ to indicate calendar time. (Thus, for example, bank $i$ 's $m$-period reported LOIS spread at time $t$ is denoted $\widehat{L}_{i m t}$.) Specifically, we estimate

$$
\widehat{L}_{i m t}=\lambda_{m t}+\phi_{t} C_{i m t}+\beta_{1, i m t} \sigma_{m t}+\beta_{2, t}\left(C_{i m t}-\bar{C}_{m t}\right)+\epsilon_{i m t}
$$

where $\epsilon_{i m t}$ is a normally distributed iid error, for each $i$ and $m$ in our sample. Since these equations are linear in the observables $C_{i m t}, \sigma_{m t}$, and $\bar{C}_{m t}$, we can use the Kalman filter to

${ }^{17}$ For modeling purposes, we take the "aggregate" Libor rate to be the cross-sectional mean $\bar{L}$. We note that this is not the same as the published figure, which is a trimmed mean, although in practice the difference is typically small.

18 See appendix A for derivation. 
infer the values of the time-varying parameters $\lambda_{m t}, \phi_{t}, \beta_{1, i m t}$, and $\beta_{2, t}$ (for all $i$ and $m$ ), the behavior of which we approximate as random walks. Estimation is joint over all 17 banks and 5 maturities, and we thus have 85 measurement equations and 92 states.

Note that we have imposed a few cross-equation restrictions to reduce the dimension of the system. First, we assume that $\phi_{t}$ is the same across all maturities. This assumption follows from our structural interpretation of $\phi$ as the ratio of recovery rates, together with an assumption that, given default, the recovery on a given claim is independent of the maturity of that claim. Second, we assume that $\beta_{2 t}$ is the same across all maturities. As shown in appendix A, this parameter is a combination of $\phi, \gamma_{2}$ and $\gamma_{3}$. Since we have already assumed that $\phi_{t}$ is independent of maturity, the assumption that $\beta_{2 t}$ does not vary with $m$ is tantamount to assuming that the cost parameters $\gamma_{2}$ and $\gamma_{3}$ do not vary with $m$. We think this is a reasonable restriction if these costs reflect primarily reputational and regulatory penalties, since there is no obvious reason that markets or regulators should care about which maturities banks are lying about. Importantly, note that we allow $\beta_{1, i m t}$ to vary across all three dimensions - time, maturity, and institution. This high degree of flexibility reflects the possibility that each bank's incentives to misreport may be different from all others' on any given day, and that, even at a particular bank on a particular day, there could be different benefits to be had by misreporting in different ways for different maturities. (In terms of the structural model, the bank-level variation in $\beta_{1, i m t}$ derives from that in $\gamma_{1, i m t}$ ).

The fixed parameters of the model are estimated by Gibbs sampling, following Kim and Nelson (1999), much in the style of the state-space modeling used in the time-varying vector autoregression literature [e.g. Cogley and Sargent (2002)]. As noted earlier, some observations are missing for some banks, either because we lack CDS data or because banks entered or departed the Libor panel. Missing observations are handled through the Kalman-filter-based imputation procedure developed in Aruoba et al. (2009). This process starts with the initial data that has missing values and uses a matrix, noted $W_{t}$ in that paper, to eliminate missing observations, creating a situation where the left- and right-hand variables in the observation equation within the filter are of a different size in each period. In our application, firms will be missing for a given observation either because they have no LOIS or CDS data for that period. Denoting the number of firms with data at time $t$ with $J_{t}$ and stacking the data across firms and maturities at each point in time, the measurement equations of the state-space representation (11) can be written compactly as

$$
\widehat{\mathbf{L}}_{t}=\mathbf{X}_{t} \theta_{t}+\varepsilon_{t}
$$

where $\widehat{\mathbf{L}}_{t}$ is the $5 J_{t} \times 1$ vector of Libor submissions across banks and maturities (recall that we are using data from five different maturities for each firm), $\mathbf{X}_{t}$ is the matrix of independent variables, and $\theta_{t}$ is the vector of time-varying coefficients. $\mathbf{X}_{t}$ is $5 J_{t} \times 92$ and has the structure

$$
\mathbf{X}_{t}=\left(\begin{array}{lll}
\mathbf{I}_{5} \otimes 1_{J_{t}} & \Sigma_{C_{m t}} & \mathbf{C}_{t}
\end{array}\left[\mathbf{C}_{t}-\overline{\mathbf{C}}_{t}\right]\right)
$$


where $\mathbf{I}_{k}$ is the $k$-dimensional identity matrix, $1_{J_{t}}$ is a vector of ones of length $J_{t}, \Sigma_{C_{m t}}$ is a $5 J_{t} \times 5 J_{t}$ block-diagonal matrix, where each block is itself a diagonal matrix in which each of the $J_{t}$ elements is a copy of $\sigma_{m t}$-the cross-sectional standard deviation of CDS spreads for maturity $m$ at time $t, \mathbf{C}_{t}$ is the $5 J_{t} \times 1$ vector containing the $C_{i m t}$ 's, and $\overline{\mathbf{C}}_{t}$ is the $5 J_{t} \times 1$ containing the $\bar{C}_{m t}$ 's stacked on top of each other (five vectors stacked on each other each of which is $\mathbf{C}_{m t} * 1_{J_{t}}$ for each maturity $m$ ).

We treat the coefficient vector as a hidden state vector that evolves according to

$$
f\left(\theta_{t+1} \mid \theta_{t}, \mathbf{Q}\right) \sim N\left(\theta_{t}, \mathbf{Q}\right) .
$$

where $\mathbf{Q}$ is the $92 \times 92$ covariance matrix of innovations in the state transition equation. Thus $f\left(\theta_{t+1} \mid \theta_{t}, \mathbf{Q}\right)$ can be represented as the driftless random walk

$$
\theta_{t}=\theta_{t-1}+\nu_{t}
$$

where $\nu_{t} \sim N(0, \mathbf{Q})$. We assume that the measurement errors $\varepsilon_{\mathbf{t}}$ are identically and independently distributed normal random variables with mean zero and covariance matrix $\mathbf{R}$, and, in order to reduce the dimensionality of the estimation, we follow standard practice by assuming that $\varepsilon_{\mathbf{t}}$ and $\nu_{t}$ are uncorrelated. Further, we assume that the covariance matrices $\mathbf{R}$ and $\mathbf{Q}$ themselves are also diagonal. ${ }^{19}$

We assume that the hyperparameters $\mathbf{R}$ and $\mathbf{Q}$ and the initial state $\theta_{0}$ are independent from each other, that the initial state is a normal random variable with mean $\bar{\theta}_{0}$ and covariance matrix $\overline{\mathbf{P}}_{0}$. We set the initial mean $\bar{\theta}_{0}$ to line up with a world in which the true LOIS spread is derived from the individual-firm CDS with identical recovery rates between bondholders and interbank lenders. That is, we set the mean of $\phi_{0}$ equal to 1 . In light of results by Youle (2013) and others, we set the intial mean of $\beta_{1, i}$ equal to -1 , implying a small amount of misreporting on average. However, we make these initial distributions quite flat, with a covariance of matrix of $\overline{\mathbf{P}}_{0}$ that has values of 10 along the diagonal and 5 along the off-diagonals. (Reasonable variants on these choices do not change the qualitative results reported below.) The prior parameterization of the hyperparameters $\mathbf{R}$ and $\mathbf{Q}$ are also set to diffuse values; each element of the diagonal is an inverse gamma with a single degree of freedom and shape parameters of $10^{-4}$. By making these priors very flat, we allow the data to drive the shape and position of the posterior distributions. We use a two-step Gibbs algorithm: (1) states given hyperparameters and (2) hyperparameters given states. See Kim and Nelson (1999) for details concerning the construction of the posterior distributions.

In our baseline results presented below, we estimate the model on weekly averages of the daily data. If our specification were the true data-generating process, the frequency of the data used should make no systematic difference for our estimates. However, if the model

$\overline{19}$ The assumption of a diagonal $\mathbf{R}$ greatly facilitates the MCMC procedure in the presence of missing data. 


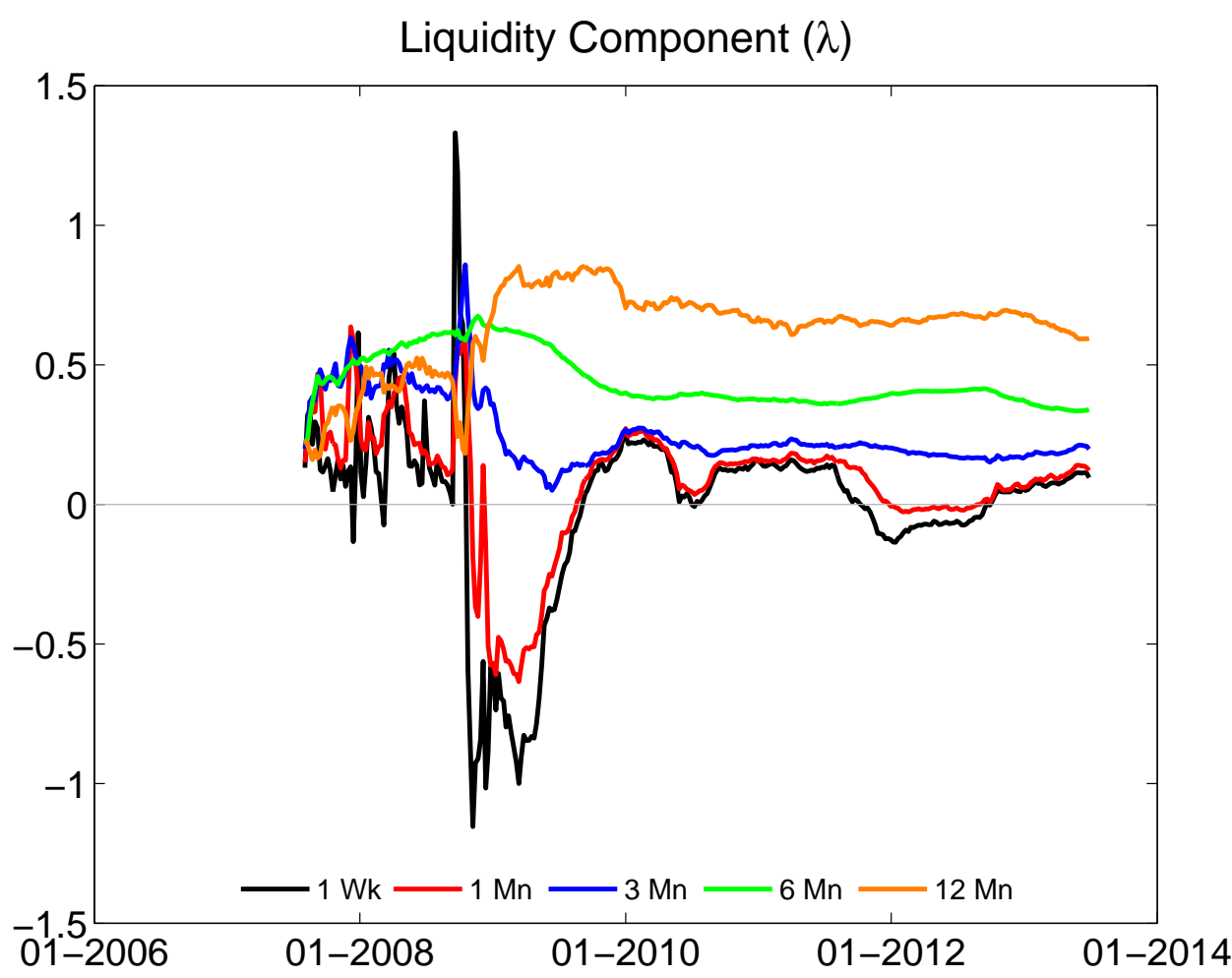

Fig. 4. Estimated Liquidity Premia Across Maturities

is misspecified - say, because the true state variables do not follow pure random walksdifferent choices for the time aggregation can matter. Our choice of weekly data as the baseline reflects a desire to minimize the high-frequency noise that seems to attend some of the daily data while still allowing the parameters to move rapidly enough to realistically capture the market's behavior. We have also run the model on monthly data with very similar results. Running the model on the daily data yields results that are similar in broad strokes but appear more dependent on priors and other details of the model specification. This may confirm that the daily data involve some high-frequency noise that disappears at higher levels of time aggregation.

\section{Results}

\subsection{State Variable Estimates}

Figure 4 shows our estimates of the liquidity premia $\lambda_{m, t}$ across maturities by plotting the medians of the posterior distributions. These premia are fairly tightly estimated and almost always significantly different from zero. For example, Figure 5 shows the 3 -month liquidity premium, with 2-standard-error bands, and compares it to the corresponding average LOIS spread. 


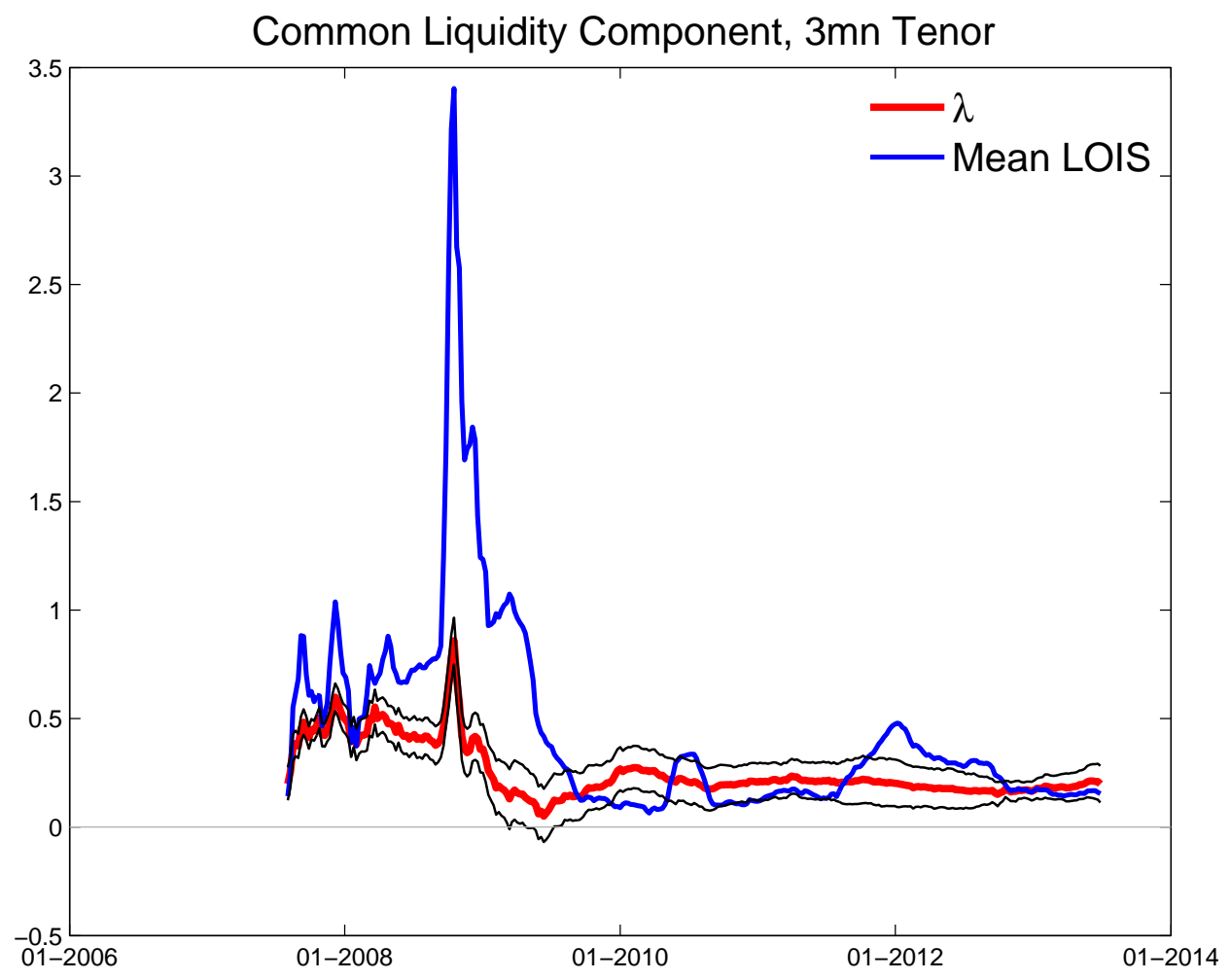

Fig. 5. 3-month liquidity premium and Libor-OIS spread

Liquidity premia are almost always monotonically increasing in maturity. This is perhaps not surprising given Figures 1 and 2, which showed the steep term structure of LOIS spreads that was not matched by the term structure of the CDS data. The one-week and one-month liquidity premia drop precipitously, and indeed take negative values, in mid-October, 2008. This observation, to which we return later, suggests that Federal Reserve interventions in funding markets around this time significantly ameliorated liquidity strains at short maturities. On the other hand, even through the end of the sample, the 6- and 12-month liquidity premia remain quite elevated relative to historical experience.

Figure 6 shows the estimated aggregate credit-risk components $\phi_{t} \bar{C}_{m t}$, and Figure 7 shows the time-varying coefficient $\phi_{t}$, with two-standard-error bands. Unlike liquidity, credit risk exhibits virtually no differences across maturities. This result is a consequence both of our assumption that relative conditional loss rates do not depend on maturity and the shape of the observed CDS curves, which, as noted earlier, tend to be quite flat at the short end.

We find that, although the credit-risk spread contributes significantly to LOIS spreads during certain episodes, it spends a significant amount of time indifferent from zero. Under the structural interpretation of our model, interbank lenders appear to perceive conditional loss rates of less than half of those of CDS holders most of the time, but that perception changes rapidly at times. In other words, the data seem to want significant variation over time in the degree to which credit risk is priced in Libor. 


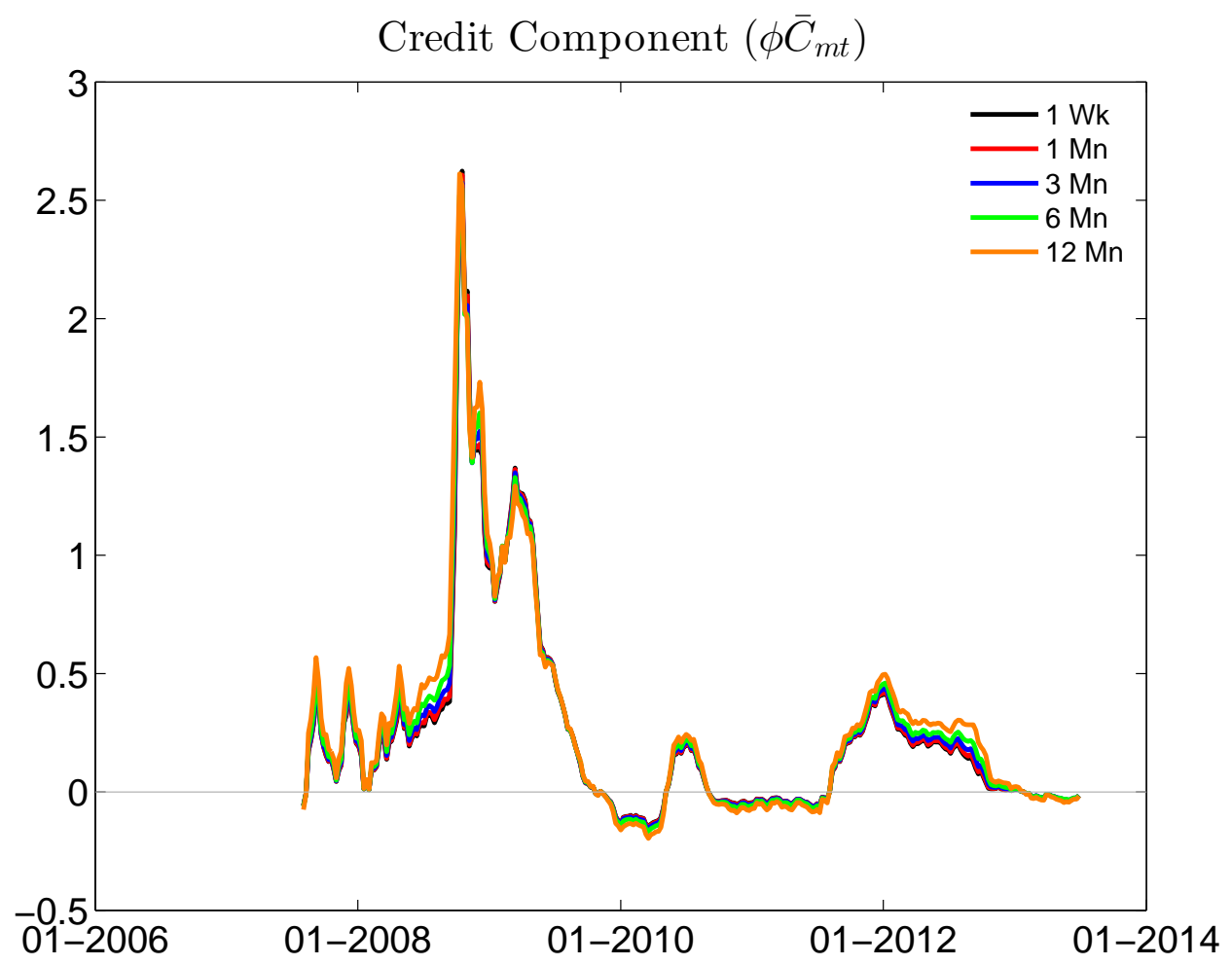

Fig. 6. Aggregate Credit-Risk Component, $\phi_{t} \bar{C}_{m t}$

Specifically, credit risk sensitivity spikes during two relatively brief episodes. The first episode is at the beginning of the financial crisis, when we estimate $\phi_{t}$ to jump to a value of approximately 5; there was only a modest effect of this jump on aggregate LOIS spreads because the value of $\bar{C}_{m t}$ was very low at that time across maturities. The second episode follows the Lehman bankruptcy. We estimate that the credit-risk component of LOIS spreads (Figure 6 ) increased sharply due to the combination of the spike in $\phi_{t}$ and the increase in CDS spreads. ${ }^{20}$ (In contrast, the notable rise in the credit risk premium a few months later, around the time of the first round of Federal Reserve bank stress tests, was due entirely to an increase in $\bar{C}_{m t}$, as $\phi_{t}$ remained constant at a moderate level.)

Figure 8 plots, at each maturity, the interquartile range of our point estimates of the reporting bias across banks. (This quantity is calculated as the sum of the last two terms in equation (10).) We find that misreporting varies considerably across banks, maturity, and time. On average, it is slightly negative, consistent with previous empirical work, but we cannot say for certain how it affected aggregate Libor reference rates because of the nonlinearities associated with the way those rates are constructed. In any case, the more striking feature of our

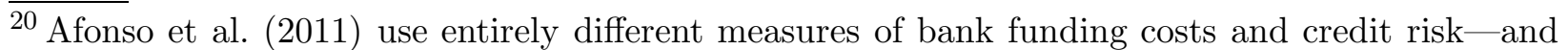
a broader sample of banks - to examine the response of the interbank market immediately after Lehman. Their results are consistent with ours in the sense that they conclude that sensitivity to credit risk increased during this period, although they argue that most of this sensitivity took the form of quantity rationing rather than differences in spreads. 


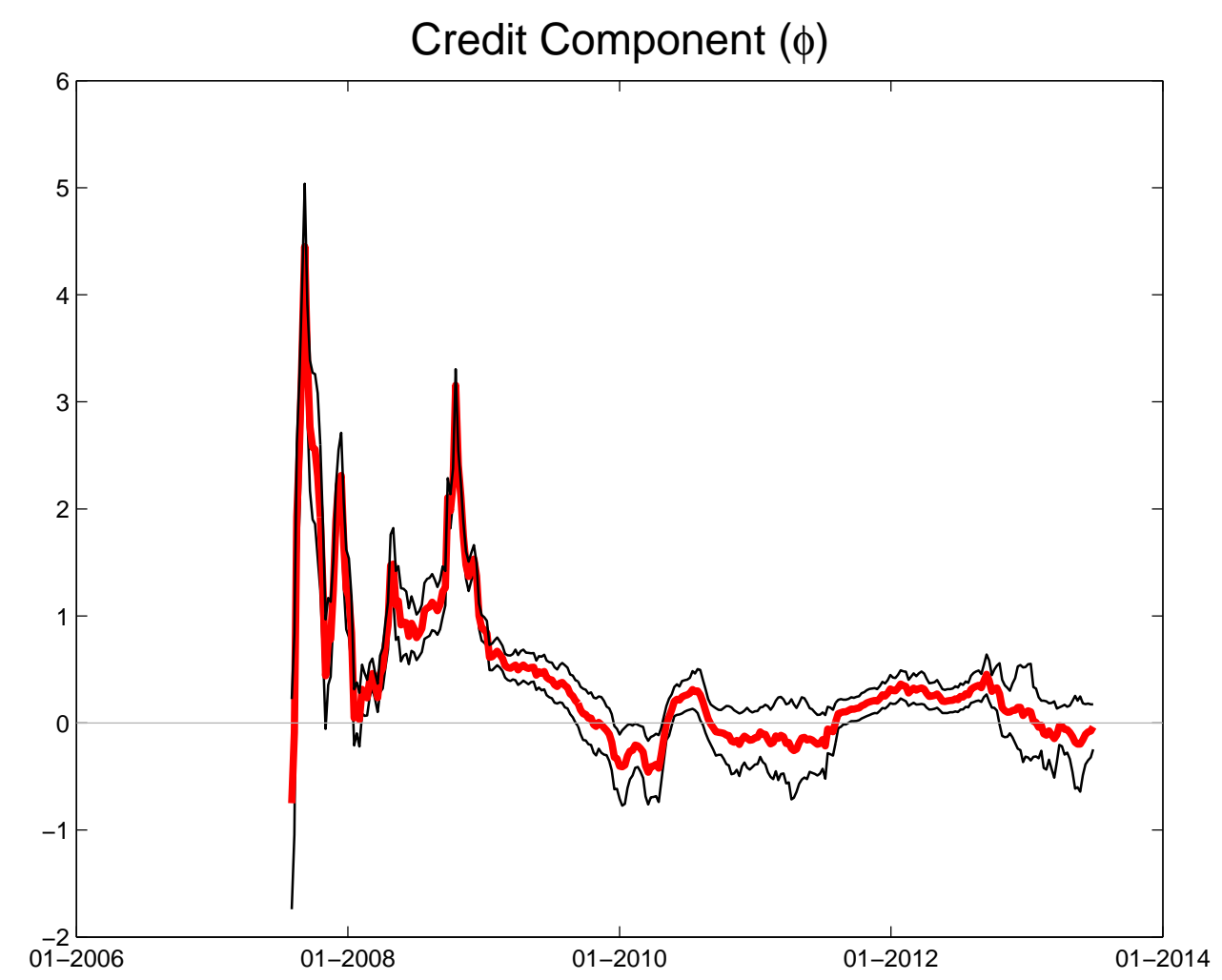

Fig. 7. Credit-Risk Sensitivity, $\phi_{t}$

estimates is that, during times of financial stress, banks appear to have misreported across a range of values, both positive and negative. This could suggest that trading profits (which could bias quotes in either direction) outweighed reputational concerns (which should only bias quotes downward), at least in some cases. The finding that this occurred more often during crisis periods is consistent with banks misreporting being opportunistic. However, we also estimate that misreporting biases were considerably smaller in the stress period of 2011 than they were in 2008-2009, even though the levels and dispersion of CDS spreads were similar in both periods, perhaps suggesting that banks have made more of an effort to report correctly in an environment of enhanced attention to this problem.

Figure 9 shows our median estimate of the ratio of $\gamma_{2, t}$, to $\gamma_{3, t}$, together with the $5^{\text {th }}$ and $95^{\text {th }}$ percentiles. This estimate is always statistically and economically close to zero, implying that the perceived cost of differing from other banks is much greater than the perceived cost of lying per se. This finding helps to explain the relatively tight cross-sectional variance of LOIS spreads compared to that of CDS spreads through both the numerator and the denominator of the ratio. All else equal, a value of $\gamma_{2}$ close to zero implies that banks do not vary their reported Libor quotes commensurately with their credit risk; meanwhile, a high value of $\gamma_{3}$ implies that all banks want to report similar values. 

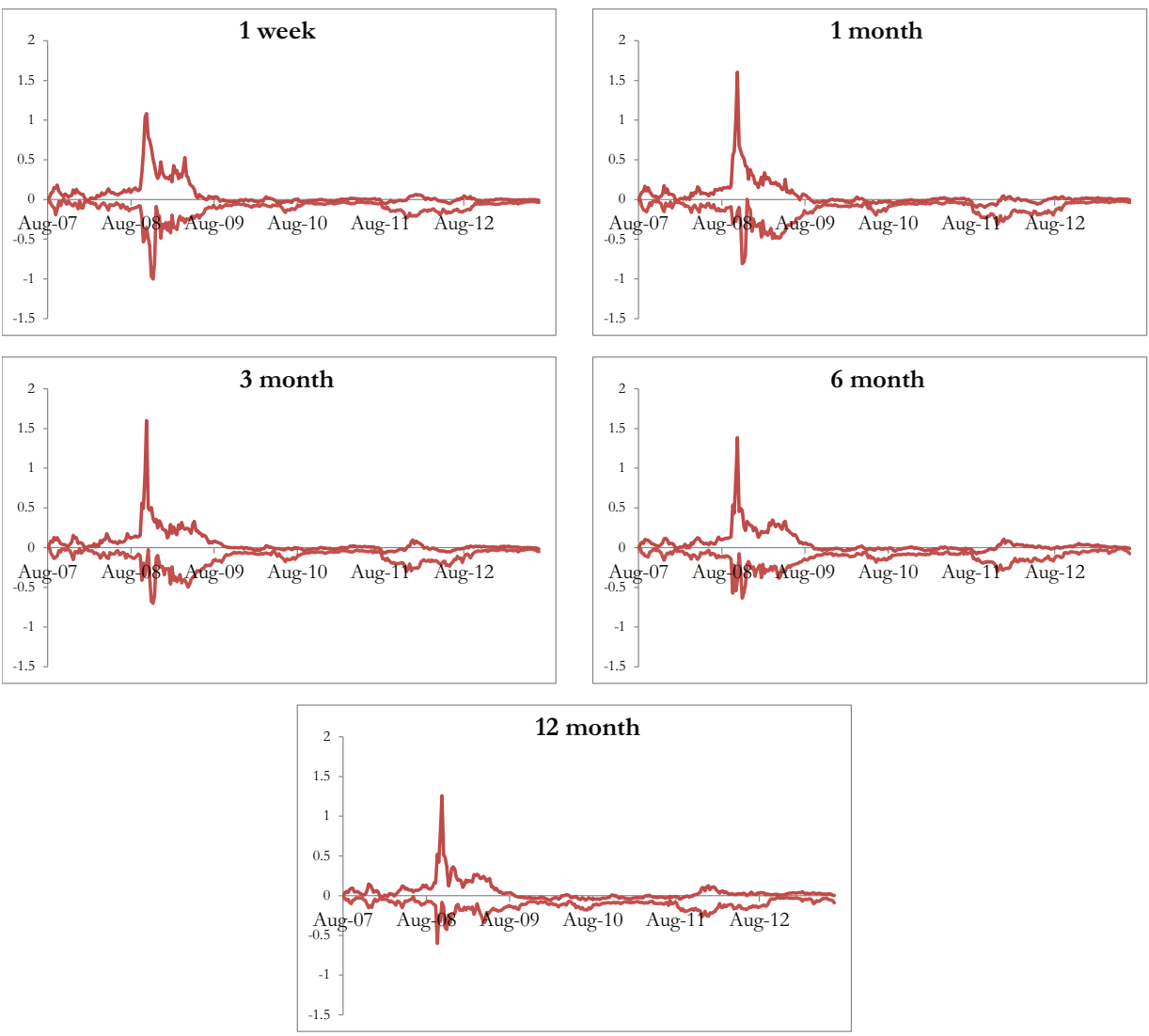

Fig. 8. Interquartile Ranges of Misreporting Bias

\subsection{Decompositions of LOIS spreads}

Table 3 summarizes the relative contributions of the liquidity, credit-risk, and misreporting components (based on our point estimates of $\lambda_{m t}$ and $\phi_{t}$ ). The top panel reports these results in terms of the average values (over time) of those components. The bottom panel reports the average values of the ratios of the three components to our estimate of the average of the "true" LOIS spread-i.e., once we have removed the estimated misreporting bias. The liquidity component dominates the true LOIS spread at all maturities greater than one week. At the 12-month horizon, it accounts for $80 \%$ of the level of that spread. The average misreporting component is modestly negative. It is similar in magnitude, on average, across maturities, although, as a fraction of the spread itself it is less important at longer maturities.

Table 4 decomposes the time-series variance of the LOIS spread, making use of the approximation

$$
\begin{aligned}
\operatorname{var}\left[\bar{L}_{m t}\right] \approx & \operatorname{var}\left[\lambda_{m t}\right]+\phi *^{2} \operatorname{var}\left[\bar{C}_{m t}\right]+\overline{C *}_{m}^{2} \operatorname{var}\left[\phi_{t}\right] \\
& +2\left(\overline{C *}_{m} \operatorname{cov}\left[\lambda_{m t}, \phi_{t}\right]+\phi * \operatorname{cov}\left[\lambda_{m t}, \bar{C}_{m t}\right]+\phi * \overline{C *}_{m} \operatorname{cov}\left[\phi_{t}, \bar{C}_{m t}\right]\right)
\end{aligned}
$$




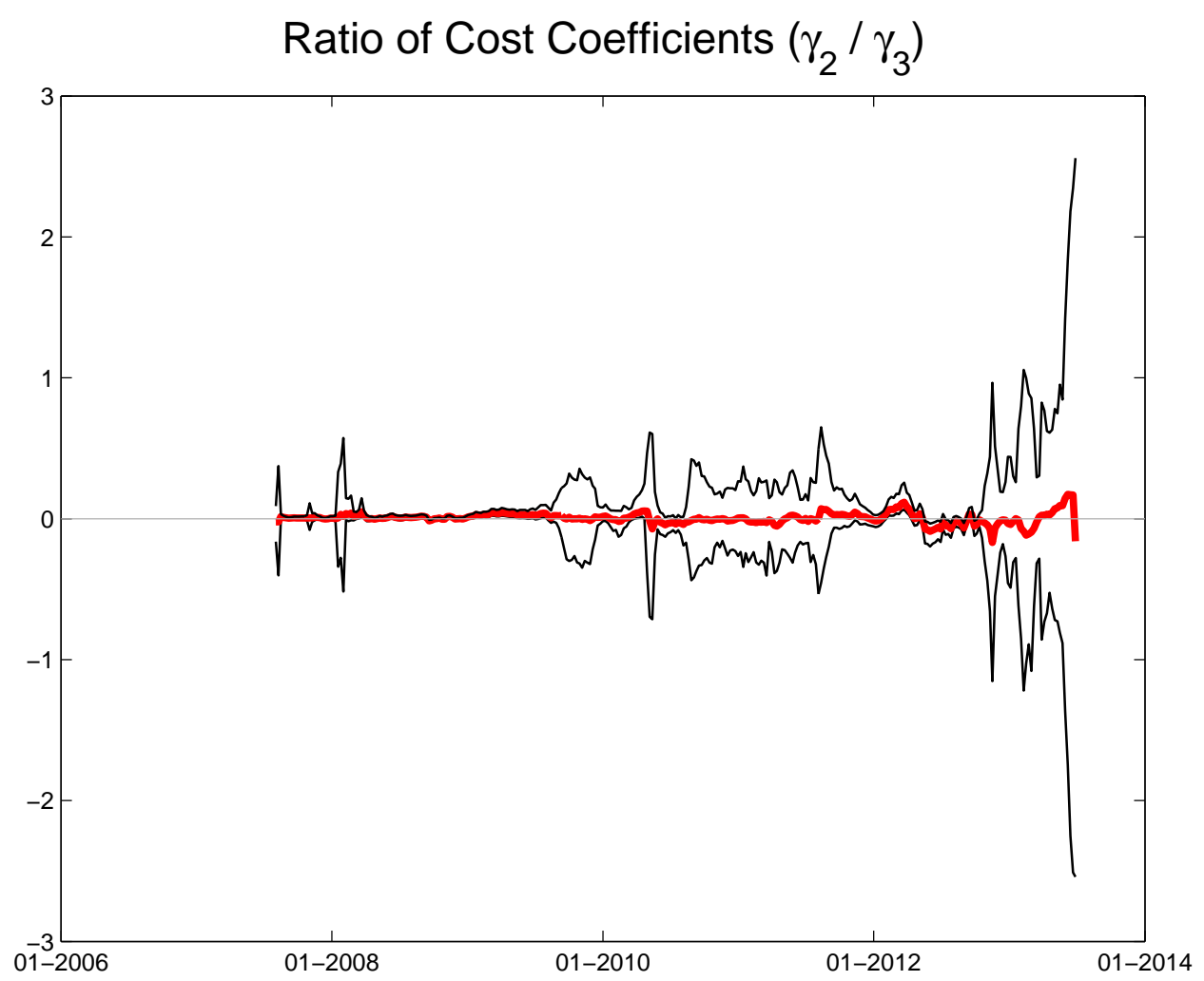

Fig. 9. Ratio of misreporting costs

where $\phi *$ and $\overline{C *}$ are linearization points chosen to maximize the fit of the linear approximation with respect to the data. Each column of the table sums to the variance of the (true) LOIS spread at each maturity, apart from approximation error from the linearization. Again, this decomposition is performed using the medians of the distributions of our estimated state variables.

Apart from the one-week maturity, the variance of LOIS spreads is dominated by the creditrisk terms. That is, although liquidity seems to be the largest component of longer-run spreads on average, it is fluctuations in the credit-risk component that drive the movements over time. In addition, movements in credit risk itself (as captured by CDS spreads) account for only about half of this variation. The other half is due to movements in credit-risk sensitivity, represented by the time-varying parameter $\phi_{t}$. As noted above, fluctuations in $\phi_{t}$ played a large role in driving LOIS spreads during the crisis. This variation would be missed in specifications that assume a constant coefficient on CDS spreads.

At the one-week horizon and, to a lesser extent, at the one-month horizon, the covariance terms in equation (16) contribute significantly to the variance of LOIS spreads, with a negative sign. In other words, negative correlation between the components of LOIS exerts a dampening effect on its volatility at the very short end of the curve. This negative correlation occurs primarily between the liquidity component $\lambda$ and the aggregate CDS spread $\bar{C}$, as shown in Table 5. In contrast, at longer maturities, this correlation is moderately positive. 
Table 3

\begin{tabular}{l|ccccc} 
& 1 wk & $\mathbf{1}$ mn & $\mathbf{3} \mathbf{~ m n}$ & $\mathbf{6} \mathbf{~ m n}$ & $\mathbf{1 2} \mathbf{~ m n}$ \\
\hline \multicolumn{6}{c}{ Average value (pp) } \\
\hline liquidity & -0.002 & 0.080 & 0.255 & 0.444 & 0.629 \\
credit risk & 0.248 & 0.251 & 0.257 & 0.266 & 0.284 \\
misreporting & -0.053 & -0.073 & -0.071 & -0.075 & -0.066 \\
\hline \multicolumn{6}{c}{ Average fraction of "true" LOIS spread } \\
\hline liquidity & $28 \%$ & $56 \%$ & $78 \%$ & $81 \%$ & $79 \%$ \\
credit risk & $72 \%$ & $44 \%$ & $22 \%$ & $19 \%$ & $21 \%$ \\
misreporting & $-32 \%$ & $-28 \%$ & $-17 \%$ & $-12 \%$ & $-7 \%$
\end{tabular}

Notes: The top panel shows the average level of each of the indicated components of the average LOIS spread at each maturity. The second panel shows the unweighted average value of each component when normalized by the contemporaneous value of the bias-corrected LOIS spread. The contributions are calculated using the medians of the posterior distributions of the estimates.

Relative contributions of model components

\begin{tabular}{l|ccccc}
\multicolumn{1}{c}{} & $\mathbf{1} \mathbf{~ w k}$ & $\mathbf{1} \mathbf{~ m n}$ & $\mathbf{3} \mathbf{~ m n}$ & $\mathbf{6} \mathbf{~ m n}$ & $\mathbf{1 2} \mathbf{~ m n}$ \\
\hline$\lambda$ & 0.100 & 0.050 & 0.016 & 0.009 & 0.023 \\
$C$ & 0.068 & 0.067 & 0.065 & 0.063 & 0.060 \\
$\phi$ & 0.058 & 0.059 & 0.062 & 0.068 & 0.085 \\
Covariance terms & -0.125 & -0.061 & 0.030 & 0.048 & -0.033 \\
\hline
\end{tabular}

Notes: The table shows the approximate contribution of each of the indicated components to the overall time-series variance of the average LOIS spread at each maturity. Units are percentage points squared. The contributions of $\lambda$ and $\phi$ are calculated

Table 4 using the medians of the posterior distributions of the estimates.

Variance decomposition of the LIBOR-OIS spread

This suggests that times of high credit risk may also be times when banks prefer to shift lending from long to short maturities or to shift borrowing from short to long maturities.

Finally, Table 6 reports the decomposition of LOIS spreads around some specific events that garnered wide attention. The first event ("Beginning of crisis") includes the suspension of redemption of funds by BNP Paribas that marked the start of the 2007-08 financial crisis and that corresponded to the sudden jump in LOIS spreads that was evident in Figure 1. The table shows that, during the month of August 2007, LOIS spreads at most maturities exhibited increases that were in the 99th percentile (given the distribution of such changes in our sample). Our decomposition shows that a small part of these increases were due to a deterioration in liquidity. Instead, most of the increase can be explained by the rise in $\phi$.

In contrast, the second and third columns of the table show the breakdown for two episodes in which the Federal Reserve responded to the crisis by introducing liquidity facilities. First, in December 2007, the Fed introduced the Term Auction Facility (TAF), which made term loans up to 90 days to depository institutions. In the weeks surrounding the TAF announce- 
Table 5

\begin{tabular}{cccccc}
\hline & $\mathbf{1} \mathbf{~ w k}$ & $\mathbf{1} \mathbf{~ m n}$ & $\mathbf{3} \mathbf{~ m n}$ & $\mathbf{6} \mathbf{~ m n}$ & $\mathbf{1 2} \mathbf{~ m n}$ \\
\hline Correlation & $-69 \%$ & $-70 \%$ & $-26 \%$ & $37 \%$ & $40 \%$ \\
\hline
\end{tabular}

Notes: The table shows time-series correlations between the average bank CDS spread and the median of the posterior distributions of our estimates of 1 at different maturities.

Correlation of credit risk and liquidity factor

ment, LOIS spreads fell across the board. We attribute a sizable portion of the fall at the oneand three-month maturities to improved liquidity. (Again, movement in $\phi$ is also estimated to have played a role.) Similarly, the Fed introduced or extended a host of liquidity facilities targeted at relatively short maturities in October 2008. ${ }^{21}$ As shown in the third column, LOIS spreads narrowed significantly around this time, and, at maturities of up to three months, our model attributes most of this narrowing to an improvement in liquidity, consistent with the Fed's measures having the desired effect. Interestingly, in both the December 2007 and October 2008 episodes, liquidity improvements at the short end of the term structure were accompanied by deterioration at the long end. This could reflect a substitution by banks into the maturities where the facilities were targeted and away from longer-term funding, which was not generally supported by these programs.

CDS spreads did not move substantially in any of the above episodes. The final two columns consider events in which they did. First, in May of 2009, the Federal Reserve announced the results of the Supervisory Capital Assessment Program (also known as the bank "stress tests"). These were generally regarded as successful, and bank CDS spreads narrowed significantly in response. Simultaneously, LOIS spreads narrowed, particularly at longer maturities, and we estimate that this occurrance was entirely due to the improvement in credit risk; we do not see any improvement in liquidity around this time. Similarly, we do not find a significant deterioration in liquidity in response to the turbulence in European sovereign debt markets that arose in August 2011, even though bank CDS spreads widened dramatically. Moreover, the CDS widening did not pass through to a significant degree into LOIS spreads because our estimate of $\phi$ was near zero around this time.

$\overline{21}$ These included the Commercial Paper Funding Facility, the Money Market Investor Funding Facility, an increase in TAF lending, and new or increased liquidity swap lines with numerous foreign central banks. 


\begin{tabular}{|c|c|c|c|c|c|c|c|c|c|c|c|}
\hline & & \multicolumn{2}{|c|}{ Beginning of crisis } & \multicolumn{2}{|c|}{ TAF } & \multicolumn{2}{|c|}{ Fed Facilities } & \multicolumn{2}{|c|}{ SCAP } & \multicolumn{2}{|c|}{ European debt crisis } \\
\hline & & \multicolumn{2}{|c|}{$\begin{array}{c}\text { Weeks of } \\
8 / 1-8 / 29 / 07\end{array}$} & \multicolumn{2}{|c|}{$\begin{array}{c}\text { Weeks of } \\
12 / 5 / 07-1 / 2 / 08\end{array}$} & \multicolumn{2}{|c|}{$\begin{array}{c}\text { Weeks of } \\
10 / 1-11 / 5 / 08\end{array}$} & \multicolumn{2}{|c|}{$\begin{array}{c}\text { Weeks of } \\
4 / 29-5 / 20 / 09\end{array}$} & \multicolumn{2}{|c|}{$\begin{array}{c}\text { Weeks of } \\
7 / 27-9 / 7 / 11\end{array}$} \\
\hline \multirow{5}{*}{ LOIS } & $1 \mathrm{wk}$ & 0.496 & & -0.273 & & -2.007 & $* * *$ & -0.046 & & 0.009 & \\
\hline & $1 \mathrm{mn}$ & 0.529 & $* *$ & -0.653 & $* * *$ & -1.004 & $* * *$ & -0.124 & & 0.042 & \\
\hline & $3 \mathrm{mn}$ & 0.541 & $* * *$ & -0.347 & $*$ & -0.633 & $* * *$ & -0.310 & * & 0.109 & \\
\hline & $6 \mathrm{mn}$ & 0.589 & $* * *$ & -0.222 & & -0.356 & $*$ & -0.333 & $* *$ & 0.134 & \\
\hline & $12 \mathrm{mn}$ & 0.454 & $* * *$ & -0.106 & & -0.277 & $*$ & -0.350 & $* * *$ & 0.169 & \\
\hline \multirow{5}{*}{$\lambda$} & $1 \mathrm{wk}$ & 0.164 & & -0.019 & & -1.838 & $* * *$ & 0.352 & & -0.113 & \\
\hline & $1 \mathrm{mn}$ & 0.182 & & -0.403 & $* * *$ & -0.729 & $* * *$ & 0.157 & & -0.027 & \\
\hline & $3 \mathrm{mn}$ & 0.174 & $* * *$ & -0.105 & $*$ & -0.240 & $* * *$ & -0.026 & & 0.004 & \\
\hline & $6 \mathrm{mn}$ & 0.194 & $* * *$ & 0.020 & & 0.056 & $* * *$ & -0.016 & & 0.006 & \\
\hline & $12 \mathrm{mn}$ & -0.035 & & 0.158 & $* * *$ & 0.281 & $* * *$ & -0.009 & & 0.003 & \\
\hline \multirow{5}{*}{ C-bar } & $1 \mathrm{wk}$ & 0.004 & & -0.013 & & 0.015 & & -0.801 & $* * *$ & 0.980 & $* * *$ \\
\hline & $1 \mathrm{mn}$ & 0.005 & & -0.011 & & -0.002 & & -0.807 & $* * *$ & 0.991 & $* * *$ \\
\hline & $3 \mathrm{mn}$ & 0.007 & & -0.007 & & -0.044 & & -0.818 & $* * *$ & 1.013 & $* * *$ \\
\hline & $6 \mathrm{mn}$ & 0.010 & & -0.003 & & -0.098 & & -0.824 & $* * *$ & 1.034 & $* * *$ \\
\hline & $12 \mathrm{mn}$ & 0.014 & & -0.001 & & -0.180 & & -0.817 & $* * *$ & 1.046 & $* * *$ \\
\hline$\phi$ & & 4.207 & $* * *$ & -1.054 & * & -0.239 & & -0.063 & & 0.198 & \\
\hline
\end{tabular}

Notes: The table shows cumulative changes in the LOIS spread and CDS spread data and in the medians of the posterior distributions of our state-variable estimates during certain episodes of interest. Asterisks indicate values that are in the top or bottom 5, 2.5, and 0.5 percentiles, based on the distributions observed during our sample period.

Table 6. Decomposition of model results across various time periods 


\section{Conclusion}

This paper has offered a decomposition of dollar Libor-OIS spreads at different maturities into components reflecting funding-market liquidity, counterparty credit risk, and strategic misreporting. Relative to previous empirical papers that also perform credit vs. liquidity decompositions, we have made three innovations: (1) making use of the bank- and maturitylevel panel data, (2) allowing credit-risk sensitivity to vary over time, and (3) accounting for possible misreporting bias. Relative to previous theoretical papers that have considered misreporting, our chief innovation is to allow for the possibility that banks perceive a cost of being outliers in the reporting distribution, rather than just costs of not telling the truth.

We conclude that, during the crisis and post-crisis period we examine, liquidity was the largest component of bank funding costs, especially at longer maturities. Furthermore, we find that, at shorter maturities, liquidity improved significantly following Federal Reserve interventions in short-term funding markets in 2008, in contrast to some previous studies such as Taylor and Williams (2009) that suggest the Fed's actions had limited effects. Apart from that episode, however, we find that most of the variation in spreads is due to the creditrisk component. One nuance of our results, relative to previous studies, is that much of the variation in the credit risk component stems from fluctuations in Libor's sensitivity to credit risk, rather than from fluctuations in the level of credit risk per se. We estimate credit-risk sensitivity to be greatest during certain periods of the financial crisis, but the reasons that it varies over time will require further study.

Meanwhile, our estimates of the bias from misreporting vary considerably across banks, maturities, and time. They are largest in magnitude during early 2009, when the dispersion of CDS spreads was also the greatest, suggesting that banks may have misreported by more during times when this activity was harder to detect. Misreporting seems to have been less of a problem in the more-recent past, consistent with increased regulatory discipline. Our estimates are consistent with the "cost of being an outlier" playing an important role in banks' rate reporting behavior, a phenomenon that can also explain the consistently low dispersion of Libor quotes relative to CDS quotes. 


\section{A Derivation of Measurement Equations}

Each bank's first-order condition is:

$$
\gamma_{1, i}-\gamma_{2}\left(\frac{\widehat{L}_{i}-L_{i}}{\operatorname{std}[\widehat{L}]}\right)-\gamma_{3}\left(\frac{\widehat{L}_{i}-\widehat{\widehat{L}}}{\operatorname{std}[\widehat{L}]}\right)=0
$$

Solving for $\widehat{L}_{i}$ and substituting equation (5) gives

$$
\widehat{L}_{i}=\frac{\gamma_{1, i} \operatorname{std}[\widehat{L}]+\gamma_{2}\left(\lambda+\phi C_{i}\right)+\gamma_{3} \overline{\widehat{L}}}{\gamma_{2}+\gamma_{3}}
$$

Taking expectations and rearranging delivers equation (9).

Substituting (9) back into (A.2) gives

$$
\widehat{L}_{i}=\lambda+\phi \frac{\gamma_{2} C_{i}+\gamma_{3} \bar{C}}{\gamma_{2}+\gamma_{3}}+\left(\frac{\gamma_{1, i}}{\gamma_{2}+\gamma_{3}}+\frac{\gamma_{3} \bar{\gamma}_{1}}{\gamma_{2}\left(\gamma_{2}+\gamma_{3}\right)}\right) \operatorname{std}[\widehat{L}]
$$

The cross-sectional variance is therefore

$$
\begin{aligned}
\operatorname{var}[\widehat{L}] & =\left(\frac{\phi \gamma_{2}}{\gamma_{2}+\gamma_{3}}\right)^{2} \sigma^{2}+\frac{\operatorname{var}[\widehat{L}] \operatorname{var}\left[\gamma_{1}\right]}{\left(\gamma_{2}+\gamma_{3}\right)^{2}} \\
& =\frac{\left(\phi \gamma_{2}\right)^{2}}{\left(\gamma_{2}+\gamma_{3}\right)^{2}-\operatorname{var}\left[\gamma_{1}\right]} \sigma^{2}
\end{aligned}
$$

Thus, we can write equation (10), by defining

$$
\beta_{1 i}=\left(\frac{\gamma_{1, i}}{\gamma_{2}+\gamma_{3}}+\frac{\gamma_{3} \bar{\gamma}_{1}}{\gamma_{2}\left(\gamma_{2}+\gamma_{3}\right)}\right) \frac{\phi \gamma_{2}}{\sqrt{\left(\gamma_{2}+\gamma_{3}\right)^{2}-\operatorname{var}\left[\gamma_{1}\right]}}
$$

and

$$
\beta_{2 m t}=-\frac{\gamma_{3}}{\gamma_{2}+\gamma_{3}}
$$

Given the estimated time-varying reduced-form parameters, we can recover the ratio of the 
cost parameters as

$$
\frac{\gamma_{2 t}}{\gamma_{3 t}}=-\frac{\beta_{2 m t}+1}{\beta_{2 m t}}
$$

\section{References}

Abrantes-Metz, Rosa M., Michael Kraten, Albert D. Metz, and Gim S. Seow, "Libor manipulation?," Journal of Banking and Finance, January 2012, 36 (1), 136-150.

Acharya, Viral V. and David Skeie, "A model of liquidity hoarding and term premia in inter-bank markets," Journal of Monetary Economics, 2011, 58 (5), 436-447.

Afonso, Gara, Anna Kovner, and Antoinette Schoar, "Stressed, Not Frozen: The Federal Funds Market in the Financial Crisis," Journal of Finance, August 2011, 66 (4), 1109-1139.

Allen, Franklin, Elena Carletti, and Douglas Gale, "Interbank market liquidity and central bank intervention," Journal of Monetary Economics, July 2009, 56 (5), 639-652.

Aruoba, S. Boraäÿan, Francis X. Diebold, and Chiara Scotti, "Real-Time Measurement of Business Conditions," Journal of Business 83 Economic Statistics, 2009, 27 (4), 417-427.

Ashcraft, Adam and Hoyt Bleakley, "On the market discipline of informationally opaque firms: evidence from bank borrowers in the federal funds market," Staff Reports 257, Federal Reserve Bank of New York August 2006.

Chen, Jiakai, "LIBORs Poker: Interbank Borrowing Costs and Strategic Reporting," October 2013. Working paper, available at: http://ssrn.com/abstract $=2136871$.

Christensen, Jens H. E., Jose A. Lopez, and Glenn D. Rudebusch, "Do Central Bank Liquidity Facilities Affect Interbank Lending Rates?," Journal of Business and Economic Statistics, January 2014, 32 (1), 136-151.

Cogley, Timothy and Thomas J. Sargent, "Evolving Post-World War II U.S. Inflation Dynamics," in "NBER Macroeconomics Annual 2001, Volume 16" NBER Chapters, National Bureau of Economic Research, Inc, 2002, pp. 331-388.

Duffie, Darrell and Jeremy C. Stein, "Reforming LIBOR and Other Financial-Market Benchmarks," September 2014. Working Paper, available at: http://www.darrellduffie.com/uploads/working/DuffieSteinLIBOR2014.pdf.

Eisenschmidt, Jens and Jens Tapking, "Liquidity risk premia in unsecured interbank money markets," March 2009. European Central Bank Working Paper, number 1025.

Eisl, Alexander, Rainer Jankowitsch, and Marti G. Subrahmanyam, "The Manipulation Potential of Libor and Euribor," June 2014. Working paper, available at: http://people.stern.nyu.edu/msubrahm/papers/LIBOR.pdf.

Filipović, Damir and Anders B. Trolle, "The Term Structure of Interbank Risk," Journal of Financial Economics, September 2013, 109 (3), 707-733.

Furfine, Craig H., "Banks as Monitors of Other Banks: Evidence from the Overnight Federal Funds Market," The Journal of Business, January 2001, 74 (1), 33-57.

Gandhi, Priyank, Benjamin Golez, Jens Carsten Jackwerth, and Alberto Plazzi, "Libor Manipulation: Cui Bono?," October 2013. Working Paper, available at: http://papers.ssrn.com/sol3/papers.cfm?abstract_id=2342075. 
Gefang, Deborah, Gary Koop, and Simon M. Potter, "Understanding liquidity and credit risks in the financial crisis," Journal of Empirical Finance, 2011, 18 (5), 903-914.

Heider, Florian, Marie Hoerova, and Cornelia Holthausen, "Liquidity hoarding and interbank market spreads: the role of counterparty risk," December 2009. European Central Bank Working Paper, number 1126.

Hou, David and David Skeie, "LIBOR: Origins, Economics, Crisis, Scandal, and Reform," March 2014. Federal Reserve Bank of New York Staff Report, number 667.

Kim, Chang-Jin and Charles R. Nelson, State-Space Models with Regime Switching: Classical and Gibbs-Sampling Approaches with Applications, Vol. 1 of MIT Press Books, The MIT Press, December 1999.

King, Thomas B., "Discipline and Liquidity in the Interbank Market," Journal of Money, Credit and Banking, March 2008, 40 (2-3), 295-317.

Kuo, Dennis, David Skeie, and James Vickery, "A Comparison of Libor to Other Measures of Bank Borrowing Costs," June 2012. Available at: http://www.newyorkfed.org/research/economists/vickery/LiborKSV_staff_webpage.pdf.

McAndrews, James, Asani Sarkar, and Zhenyu Wang, "The effect of the Term Auction Facility on the London Inter-Bank Offered Rate," July 2008. Federal Reserve Bank of New York Staff Reports, number 335.

Michaud, François-Louis and Christian Upper, "What drives interbank rates? Evidence from the Libor panel," BIS Quarterly Review, March 2008.

Nelson, Charles R and Andrew F Siegel, "Parsimonious Modeling of Yield Curves," The Journal of Business, October 1987, 60 (4), 473-89.

Schwarz, Krista, "Mind the Gap: Disentangling Credit and Liquidity in Risk Spreads," May 2014. Working paper, available at http://finance.wharton.upenn.edu/ kschwarz/Spreads.pdf.

Smith, Josephine, "The Term Structure of Money Market Spreads During the Financial Crisis," November 2012. Working paper, available at: http://people.stern.nyu.edu/jsmith/TermStructureMoneyMarketSpreads.pdf.

Snider, Connan Andrew and Thomas Youle, "The Fix Is in: Detecting Portfolio Driven Manipulation of the Libor," December 2012. Working paper, available at: http://ssrn.com/abstract $=2189015$.

Taylor, John B. and John C. Williams, "A Black Swan in the Money Market," American Economic Journal: Macroeconomics, January 2009, 1 (1), 58-83.

Wu, Tao, "The U.S. Money Market and the Term Auction Facility in the Financial Crisis of 2007-2009," The Review of Economics and Statistics, May 2011, 93 (2), 617-631.

Youle, Thomas, "How Much Did Manipulation Distort the Libor?," January 2014. Working paper, available at: http://www.dartmouth.edu/ tyoule/documents/JMP49_0112.pdf. 


\section{Working Paper Series}

A series of research studies on regional economic issues relating to the Seventh Federal Reserve District, and on financial and economic topics.

Corporate Average Fuel Economy Standards and the Market for New Vehicles

WP-11-01

Thomas Klier and Joshua Linn

The Role of Securitization in Mortgage Renegotiation

WP-11-02

Sumit Agarwal, Gene Amromin, Itzhak Ben-David, Souphala Chomsisengphet, and Douglas D. Evanoff

Market-Based Loss Mitigation Practices for Troubled Mortgages

Following the Financial Crisis

Sumit Agarwal, Gene Amromin, Itzhak Ben-David, Souphala Chomsisengphet, and Douglas D. Evanoff

Federal Reserve Policies and Financial Market Conditions During the Crisis

WP-11-04

Scott A. Brave and Hesna Genay

The Financial Labor Supply Accelerator

WP-11-05

Jeffrey R. Campbell and Zvi Hercowitz

Survival and long-run dynamics with heterogeneous beliefs under recursive preferences Jaroslav Borovička

WP-11-06

A Leverage-based Model of Speculative Bubbles (Revised)

WP-11-07

Gadi Barlevy

Estimation of Panel Data Regression Models with Two-Sided Censoring or Truncation Sule Alan, Bo E. Honoré, Luojia Hu, and Søren Leth-Petersen

Fertility Transitions Along the Extensive and Intensive Margins

Daniel Aaronson, Fabian Lange, and Bhashkar Mazumder

Black-White Differences in Intergenerational Economic Mobility in the US

WP-11-10

Bhashkar Mazumder

Can Standard Preferences Explain the Prices of Out-of-the-Money S\&P 500 Put Options?

Luca Benzoni, Pierre Collin-Dufresne, and Robert S. Goldstein

WP-11-11

Business Networks, Production Chains, and Productivity:

A Theory of Input-Output Architecture

WP-11-12

Ezra Oberfield

Equilibrium Bank Runs Revisited

WP-11-13

Ed Nosal

Are Covered Bonds a Substitute for Mortgage-Backed Securities?

WP-11-14

Santiago Carbó-Valverde, Richard J. Rosen, and Francisco Rodríguez-Fernández

WP-11-15

The Cost of Banking Panics in an Age before "Too Big to Fail"

Benjamin Chabot 


\section{Working Paper Series (continued)}

Import Protection, Business Cycles, and Exchange Rates:

Evidence from the Great Recession

WP-11-16

Chad P. Bown and Meredith A. Crowley

Examining Macroeconomic Models through the Lens of Asset Pricing

WP-12-01

Jaroslav Borovička and Lars Peter Hansen

The Chicago Fed DSGE Model

WP-12-02

Scott A. Brave, Jeffrey R. Campbell, Jonas D.M. Fisher, and Alejandro Justiniano

Macroeconomic Effects of Federal Reserve Forward Guidance

WP-12-03

Jeffrey R. Campbell, Charles L. Evans, Jonas D.M. Fisher, and Alejandro Justiniano

Modeling Credit Contagion via the Updating of Fragile Beliefs

WP-12-04

Luca Benzoni, Pierre Collin-Dufresne, Robert S. Goldstein, and Jean Helwege

Signaling Effects of Monetary Policy

WP-12-05

Leonardo Melosi

Empirical Research on Sovereign Debt and Default

WP-12-06

Michael Tomz and Mark L. J. Wright

Credit Risk and Disaster Risk

WP-12-07

François Gourio

From the Horse's Mouth: How do Investor Expectations of Risk and Return

Vary with Economic Conditions?

WP-12-08

Gene Amromin and Steven A. Sharpe

Using Vehicle Taxes To Reduce Carbon Dioxide Emissions Rates of

New Passenger Vehicles: Evidence from France, Germany, and Sweden

WP-12-09

Thomas Klier and Joshua Linn

Spending Responses to State Sales Tax Holidays

WP-12-10

Sumit Agarwal and Leslie McGranahan

Micro Data and Macro Technology

WP-12-11

Ezra Oberfield and Devesh Raval

The Effect of Disability Insurance Receipt on Labor Supply: A Dynamic Analysis

WP-12-12

Eric French and Jae Song

Medicaid Insurance in Old Age

WP-12-13

Mariacristina De Nardi, Eric French, and John Bailey Jones

WP-12-14

Fetal Origins and Parental Responses

Douglas Almond and Bhashkar Mazumder 


\section{Working Paper Series (continued)}

Repos, Fire Sales, and Bankruptcy Policy

WP-12-15

Gaetano Antinolfi, Francesca Carapella, Charles Kahn, Antoine Martin,

David Mills, and Ed Nosal

Speculative Runs on Interest Rate Pegs

The Frictionless Case

WP-12-16

Marco Bassetto and Christopher Phelan

Institutions, the Cost of Capital, and Long-Run Economic Growth:

Evidence from the 19th Century Capital Market

WP-12-17

Ron Alquist and Ben Chabot

Emerging Economies, Trade Policy, and Macroeconomic Shocks

WP-12-18

Chad P. Bown and Meredith A. Crowley

The Urban Density Premium across Establishments

WP-13-01

R. Jason Faberman and Matthew Freedman

Why Do Borrowers Make Mortgage Refinancing Mistakes?

WP-13-02

Sumit Agarwal, Richard J. Rosen, and Vincent Yao

Bank Panics, Government Guarantees, and the Long-Run Size of the Financial Sector:

Evidence from Free-Banking America

WP-13-03

Benjamin Chabot and Charles C. Moul

Fiscal Consequences of Paying Interest on Reserves

WP-13-04

Marco Bassetto and Todd Messer

Properties of the Vacancy Statistic in the Discrete Circle Covering Problem

WP-13-05

Gadi Barlevy and H. N. Nagaraja

Credit Crunches and Credit Allocation in a Model of Entrepreneurship

WP-13-06

Marco Bassetto, Marco Cagetti, and Mariacristina De Nardi

Financial Incentives and Educational Investment:

The Impact of Performance-Based Scholarships on Student Time Use

WP-13-07

Lisa Barrow and Cecilia Elena Rouse

The Global Welfare Impact of China: Trade Integration and Technological Change

Julian di Giovanni, Andrei A. Levchenko, and Jing Zhang

WP-13-08

Structural Change in an Open Economy

WP-13-09

Timothy Uy, Kei-Mu Yi, and Jing Zhang

The Global Labor Market Impact of Emerging Giants: a Quantitative Assessment

WP-13-10

Andrei A. Levchenko and Jing Zhang 


\section{Working Paper Series (continued)}

Size-Dependent Regulations, Firm Size Distribution, and Reallocation

WP-13-11

François Gourio and Nicolas Roys

Modeling the Evolution of Expectations and Uncertainty in General Equilibrium

WP-13-12

Francesco Bianchi and Leonardo Melosi

Rushing into American Dream? House Prices, Timing of Homeownership, and Adjustment of Consumer Credit

Sumit Agarwal, Luojia Hu, and Xing Huang

WP-13-13

The Earned Income Tax Credit and Food Consumption Patterns

WP-13-14

Leslie McGranahan and Diane W. Schanzenbach

Agglomeration in the European automobile supplier industry

WP-13-15

Thomas Klier and Dan McMillen

Human Capital and Long-Run Labor Income Risk

WP-13-16

Luca Benzoni and Olena Chyruk

The Effects of the Saving and Banking Glut on the U.S. Economy

WP-13-17

Alejandro Justiniano, Giorgio E. Primiceri, and Andrea Tambalotti

A Portfolio-Balance Approach to the Nominal Term Structure

WP-13-18

Thomas B. King

Gross Migration, Housing and Urban Population Dynamics

WP-13-19

Morris A. Davis, Jonas D.M. Fisher, and Marcelo Veracierto

Very Simple Markov-Perfect Industry Dynamics

WP-13-20

Jaap H. Abbring, Jeffrey R. Campbell, Jan Tilly, and Nan Yang

Bubbles and Leverage: A Simple and Unified Approach

WP-13-21

Robert Barsky and Theodore Bogusz

The scarcity value of Treasury collateral:

Repo market effects of security-specific supply and demand factors

WP-13-22

Stefania D'Amico, Roger Fan, and Yuriy Kitsul

Gambling for Dollars: Strategic Hedge Fund Manager Investment

WP-13-23

Dan Bernhardt and Ed Nosal

Cash-in-the-Market Pricing in a Model with Money and

Over-the-Counter Financial Markets

WP-13-24

Fabrizio Mattesini and Ed Nosal

An Interview with Neil Wallace

WP-13-25

David Altig and Ed Nosal 


\section{Working Paper Series (continued)}

Firm Dynamics and the Minimum Wage: A Putty-Clay Approach

WP-13-26

Daniel Aaronson, Eric French, and Isaac Sorkin

Policy Intervention in Debt Renegotiation:

Evidence from the Home Affordable Modification Program

WP-13-27

Sumit Agarwal, Gene Amromin, Itzhak Ben-David, Souphala Chomsisengphet, Tomasz Piskorski, and Amit Seru

The Effects of the Massachusetts Health Reform on Financial Distress

WP-14-01

Bhashkar Mazumder and Sarah Miller

Can Intangible Capital Explain Cyclical Movements in the Labor Wedge?

WP-14-02

François Gourio and Leena Rudanko

Early Public Banks

William Roberds and François R. Velde

WP-14-03

Mandatory Disclosure and Financial Contagion

WP-14-04

Fernando Alvarez and Gadi Barlevy

The Stock of External Sovereign Debt: Can We Take the Data at 'Face Value'?

WP-14-05

Daniel A. Dias, Christine Richmond, and Mark L. J. Wright

Interpreting the Pari Passu Clause in Sovereign Bond Contracts:

It's All Hebrew (and Aramaic) to Me

WP-14-06

Mark L. J. Wright

AIG in Hindsight

WP-14-07

Robert McDonald and Anna Paulson

WP-14-08

On the Structural Interpretation of the Smets-Wouters "Risk Premium" Shock

Jonas D.M. Fisher

Human Capital Risk, Contract Enforcement, and the Macroeconomy

WP-14-09

Tom Krebs, Moritz Kuhn, and Mark L. J. Wright

Adverse Selection, Risk Sharing and Business Cycles

WP-14-10

Marcelo Veracierto

Core and 'Crust': Consumer Prices and the Term Structure of Interest Rates

WP-14-11

Andrea Ajello, Luca Benzoni, and Olena Chyruk

The Evolution of Comparative Advantage: Measurement and Implications

WP-14-12 Andrei A. Levchenko and Jing Zhang 


\section{Working Paper Series (continued)}

Saving Europe?: The Unpleasant Arithmetic of Fiscal Austerity in Integrated Economies Enrique G. Mendoza, Linda L. Tesar, and Jing Zhang

WP-14-13

Liquidity Traps and Monetary Policy: Managing a Credit Crunch

WP-14-14

Francisco Buera and Juan Pablo Nicolini

Quantitative Easing in Joseph’s Egypt with Keynesian Producers

WP-14-15

Jeffrey R. Campbell

Constrained Discretion and Central Bank Transparency

WP-14-16

Francesco Bianchi and Leonardo Melosi

Escaping the Great Recession

WP-14-17

Francesco Bianchi and Leonardo Melosi

WP-14-18

More on Middlemen: Equilibrium Entry and Efficiency in Intermediated Markets

Ed Nosal, Yuet-Yee Wong, and Randall Wright

Preventing Bank Runs

WP-14-19

David Andolfatto, Ed Nosal, and Bruno Sultanum

The Impact of Chicago's Small High School Initiative

WP-14-20

Lisa Barrow, Diane Whitmore Schanzenbach, and Amy Claessens

Credit Supply and the Housing Boom

WP-14-21

Alejandro Justiniano, Giorgio E. Primiceri, and Andrea Tambalotti

WP-14-22

The Effect of Vehicle Fuel Economy Standards on Technology Adoption

Thomas Klier and Joshua Linn

What Drives Bank Funding Spreads?

WP-14-23

Thomas B. King and Kurt F. Lewis 